
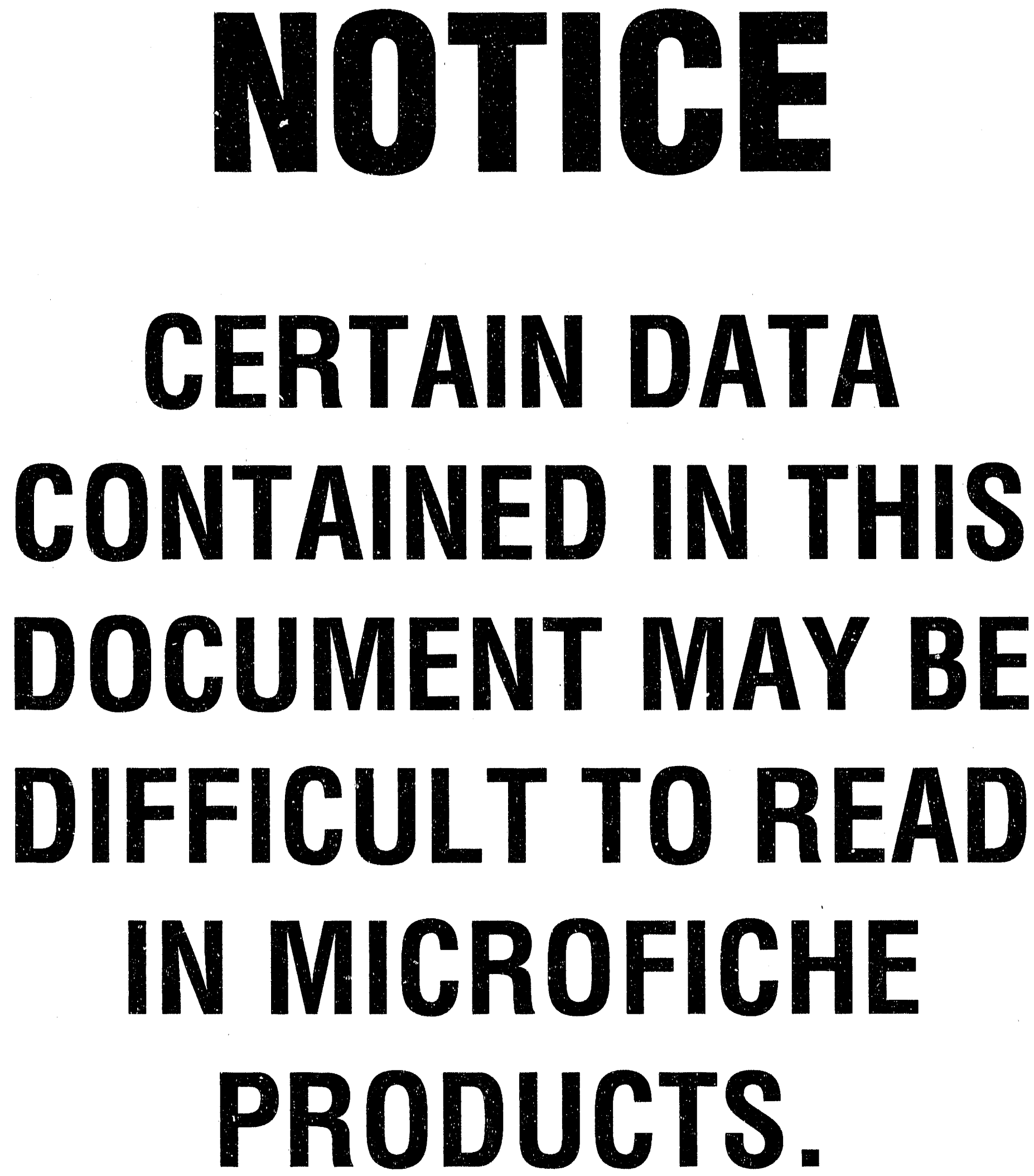


\section{U.S. DEPARTMENT OF ENERGY \\ RESPONSE TO STANDARDS FOR \\ REMEDIAL ACTIONS AT INACTIVE \\ URANIUM PROCESSING SITES; PROPOSED RULE}

January 29,1988

\section{DISCLAIMER}

This report was prepared as an account of work sponsored by an agency of the United States Government. Neither the United States Government nor any agency thereof, nor any of their employees, makes any warranty, express or implied, or assumes any legal liability or responsibility for the accuracy, completeness, or usefulness of any information, apparatus, product, or process disclosed, or represents that its use would not infringe privately owned rights. Reference herein to any specific commercial product, process, or service by trade name, trademark, manufacturer, or otherwise does not necessarily constitute or imply its endorsement, recommendation, or favoring by the United States Government or any agency thereof. The views and opinions of authors expressed herein do not necessarily state or reflect those of the United States Government or any agency thereof.

\section{MIASTER}

DSTRIBUTION OF THIS DOCUMENT IS UNLIR:" 


\section{EXECUTIVE SUMMARY}

The U.S. Environmental Protection Agency (EPA) proposed standards to replace those set aside by the U.S. Tenth Circuit Court of Appeals on September 3 , 1985. The standards establish general groundwater criteria applicable to Uranium Mill Tailings Radiation Control Act (UMTRCA) Title I sites. The standard may also constitute applicable or relevant and appropriate requirements (ARARS) for remedial actions at other U.S. Department of Energy (DOE) sites and facilities.

The proposed standards have their principal genesis in the Resource Conservation and Recovery ACt (RCRA). The standards incorporate the RCRA philosophy of complete containment and isolation of wastes from the enviroment with technologies that may have significant human involvement (i.e., maintenance) following disposal. These regulations define the point of compliance (POC) and provide corresponding guidance for alternate concentration limits (ACLS) based on this philosophy. The UMTRCA standards specify a design life of 1000 years, to the extent reasonably achievable, and, in any case, for at least 200 years. The UMTRCA Title I disposal philosophy derived from 40 CFR Part 192 involves minimum post-construction maintenance. Moreover, complete isolation of the tailings from the subsurface environment is not, as for RCRA disposal, an integral part of the design philosophy. These different philosophical approaches to the design of RCRA and Title I disposal sites have led to what the DOE believes are conflicting requirements with respect to implementing longevity requirements and meeting the proposed groundwater protection standards based on the strict application of RCRA provisions. The proposed standards also draw upon criteria for applying supplemental standards from the Superfund Amendments and Reauthorization Act of 1986 (SARA) that have yet to be successfully implemented (i.e.. technical impracticability, excessive environmental harm, and class III groundwaters).

The DOE supports the basic intent of the proposed standards to protect human heaith and the environment. However, because the EPA has elected not to evaluate the health and enviromental benefits to be derived from the imposition of the proposed standards, interpretation problems in those areas where the implementers have the responsibility under the standards to judge the reasonableness of certain actions may arise. Therefore, the DOE believes that the implementers ' task would be facilitated by an EPA description of the benefits of this major groundwater protection policy. With this description, the DOE proposals for greater flexibility and other requested modifications discussed below could be better assessed in terms of jrotection of human health and the environment.

The DOE believes that the proposed standards should be modified to enable the RCRA design approach and SARA supplemental standards to be more appropriateIy implemented within the UMTRCA Title I [Uranium Mill Tailings Remedial Action (UMTRA) Project] regulatory framework. The DOE is of the opinion that some provisions of the proposed EPA standards would lead to design requirements that are fapossible to implement and to unnecessary costs. However, these provisions can be modified in a way that would allow implementation and protection of human healih and the enviroment wile avoiding excessive costs. Therefore, the DOE requests that several provisions that are germane to the successful implementation of the intent of the proposed standards be included in the final rule. These include: 
- The POC at a disposal site should be defined at some distance downgradient from the edge of the pile and should include the intervening geology as part of the waste management area. Mixing, dispersion, and geochemical attenuation could decrease the leachate concentrations to the maximum concentration limits (MCLS) at such \& POC while providing for the protection of human health and the envirorment. (Without modification, the proposed disposal standard could be unachievable at most UMTRA Project disposal sites.)

- Specific guidance to the U.S. Nuclear Regulatory Commission (NRC) is needed in setting and implementing ACLs. Guidance consistent with cur rent RCRA ACL guidance and the following modifications should be developed:

- Institutional controls, coupled with the concept of the Point of Human Exposure for Class II waters should be permitted, rather than the Point of "Environmental" Exposure, as is currently used.

- ACLs should explicitiy apply for periods beyond the remedial action and post-closure periods.

- Existing contaminant plumes should be permitted to increase in size during perioas of passive restoration when human health and the environment are protected.

- Additional flexibility should be provided in the classification of groundwaters and/or the application of standards to take into consideration circumstances when future use of groundwater is highly unlikely. For example, a provision could be added to allow classification of groundwater as class III when the water would otherwise be low-quality Class II if there is an abundant, alternate source of higher-quality water readily available, or in cases where the source of groundwater was the milling operation (i.e., Ambrosia Lake, New Mexico, site).

- There should be a mechanism for dealing reasonably with exceptional circumstances when the costs of remedial actions for groundwater would be clearly, unreasonably high relative to the long-term benefits. The supplemental standards have such provisions for cleanup of lands and buildings. A similar provision is requested for cleanup of groundwater.

- A "grandfather clause" for completed or substantially completed sites that perform as designed should be included to exempt them from future design and construction changes.

The DOE also requests that the final standards include the following:

- 40 CFR Part. 192.22(d) should be clarified. This section could be construed to require groundwater restoration when it is technically impracticable to meet the standard or when Class III waters exist, even when human health and the environment are protected. 
- Flexibility should be provided to determine the need for, and extent of, post-disposal monitoring. At some disposal sites monitoring would not be practical since the depth to groundwater is so great that migration from the disposal site could not be detected for hundreds of years.

- 40 CFR Part 192.02(c), requiring corrective action, should be modified to include the setting of ACLS or supplemental standards. Mandatory corrective action in response to an exceedance of a standard may not be necessary to protect human health and the enviroment.

- The need for characterization, cleanup, and monitoring at vicinity properties should be clarified. Without clarification, the standard can be interpreted to require such activities at all vicinity properties.

The DOE supports the following provisions of the proposed standards and encourages their inclusion in the final standards:

- The listing of major constituents and appropriate concentration limits.

- The use of liners only when appropriate.

- Provisions for release of land prior to groundwater restoration.

- Allowance for the DOE and the NRC to develop the concept of technical impracticability on a site-specific basis.

- The use of institutional controls ano the 100-year remedial period.

- The use of natural cleansing as a means of restoration.

In summary, the DOE supports the basic intent of the proposed standards to protect human health and the environment. However, if the DOE's proposed changes and clarifications for implementation are not made, the UMTRA Project implementation cost for the groundwater restoration alone could be well in excess of $\$ 1$ billion ( 1987 dollars). As ARARs to other DOE remedial programs (and possibly non-DDE remecial programs), promulgation of the proposed standards could increase this cost by hundreds of millions of dollars. Given these potentially high costs, the increasing pressures on the Federal budget, and the tucreasing competition for waste cleanup funds, it is especially important that limited waste cleanup funds be expended at sites having relatively high impacts on human health and the enviroment. 
TABLE OF CONTENTS

Section

Page

EXECUTIVE SUMMARY

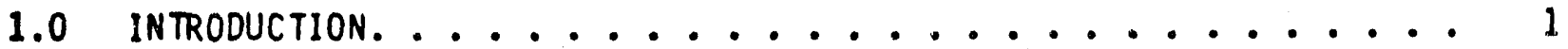

2.0 OVERVIEW OF PRCPOSFD STANDARDS. . ............. 3

3.0 ASSESSMENT OF IMPACT OF DISPOSAL SITE STANDARDS . . . . . . . 7

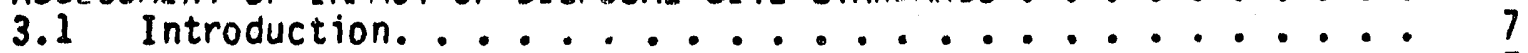

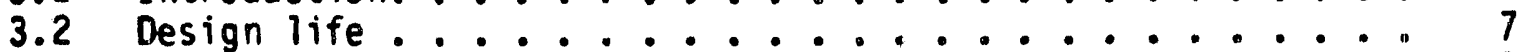

3.2.1 UMTRA Project piles ............ 8

3.2.2 RCRA and other disposal designs......... 8

3.2.3 Application to the UMTRA Project. ........ 12

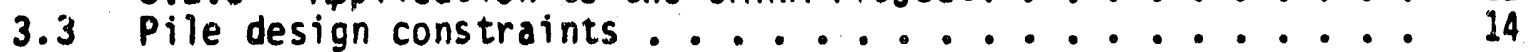

3.4 Liners and covers ............... 15

3.5 Alternative pile design enhancements.......... I6

3.6 Application of ACLs to disposal facility design ...... 18

3.7 Examples of technical impracticability

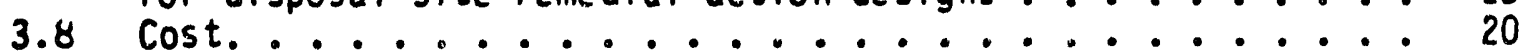

4.0 ASSESSMENT OF IMPACTS OF GROUNDWATER RESTORATION. . . . . . . 21

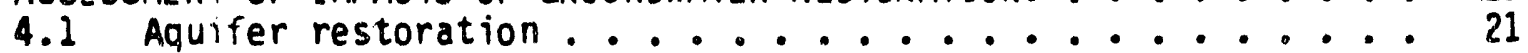

4.2 Preliminary aquifer restoration modelling ........ 21

4.3 Post-disposal monitoring requirements ......... 25

4.4 Other cost impacts................ 25

5.0 ASSESSMENT OF IMPACTS OF SUPPLEMENTAL STANDARDS . . . . . . . 29

5.1 Introduction. . . . . . . . . . . . . . 29

5.2 Environmental harm. ............ 29

5.3 Technical impracticability................. 29

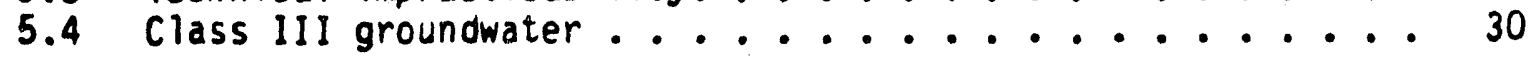

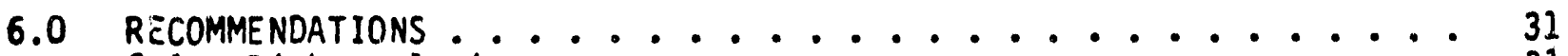

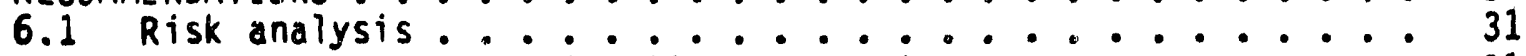

6.2 Altenate concentration limits (ACLs) ......... 31

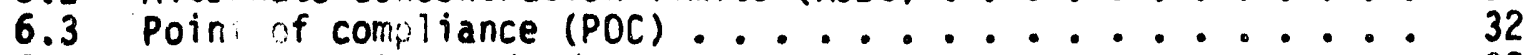

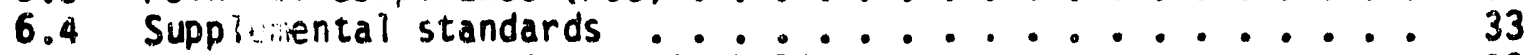

6.4.1 Technical impracticability. ........... 33

6.4.2 Supplemental standards exclusion. ......... 34

6.4.3 Consideration of costs and benefits....... 35

6.4 .4 Class III waters............... 35

6.5 Post-disposal monitoring................ 36

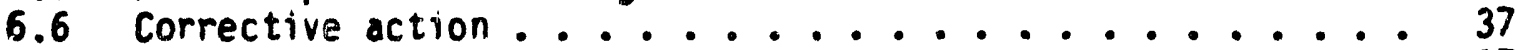

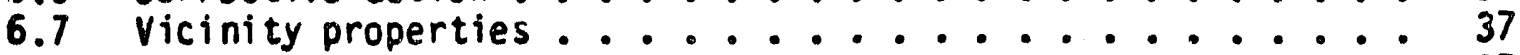

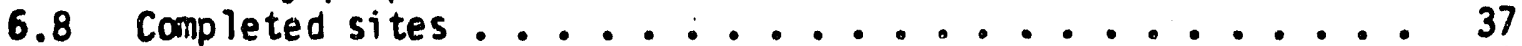

6.9 Other DOE remedial programs............. 38 


\section{TABLE OF CONTENTS (Concluded)}

Section

7.0 RESPONSES TO EPA qUESTIONS. . . . . . . . . . . . 39

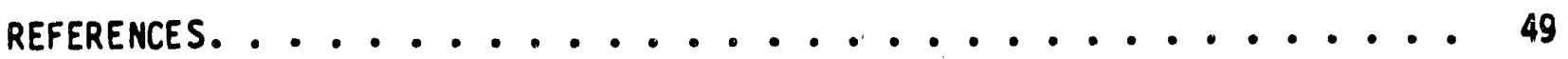

APPENDIX A - AQUIFER RESTORATION AND POST-DISPOSAL MONITORING CONSIDERATIONS AND R.OST ESTIMATES 


\section{LIST OF FIGURES}

Figure

Page

3.1 Typical UMTRA Project pile layout .................... 9

3.2 UMTRA Project pile remedial action

infiltration alla groundwater interaction. .......... 10

3.3 Comparison of limits and precipitation diversion of UMTRA Project and RCRA facilities. . . . . . . . . 11

3.4 Typical mixeo low-level waste site............... i3

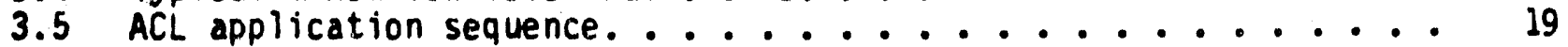

\section{LIST OF TABLES}

Table

Page

4.1 Aquifer restoration description and duration. . . . . . . . 23

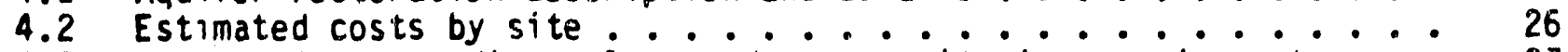

4.3 Comparative post-disposal groundwater monitoring requirements . . . 27 


\subsection{INTRODUCTION}

The Title I groundwater standards for inactive uranium mill tailings sites, wich were promulgated on January 5, 1983, by the U.S. Environmental Protection Agency (EPA) for the Uranium Mill Tailings Remedial Action (UMTRA) Project, were remanded to the EPA on September 3,1985, by the U.S. Tenth Circuit court of Appeals. The Court instructed the EPA to compile general groundwater standards for all Title I sites. On September 24, 1987, the EPA published proposed standards (52FR36000-36008) in response to the remand. This report includes an evaluation of the potential effects of the proposed EPA groundwater standards on the UMTRA Project. as well as a discussion of the DOE's position on the proposed standards. The report also contains an appendix which provides supporting information and cost analyses.

This report results from a study undertaken to: (1) determine the impacts of the proposed standards on the UMTRA Project specifically, and other DOE remedial programs in general; and (2) recommend provisions for the implementation of the final standards that will minimize adverse impacts to the conduct of the UMTRA Project and other DOE programs while ensuring protection of human health and the environment. Specifically, the following issues were considered:

- The apparent flexibility of the proposed standards.

- Various interpretations of the proposed standards.

- The extent of aquifer restoration that could be required to implement the proposed standards at each site.

- The costs of aquifer restoration.

- The disposal site design changes that might be necessary to meet the standards.

As a result of this study, the DOE's position is to: (1) support the intent of the proposed EPA standards; (2) request modifications to provide additional flexibility and recommend clarification of certain issues in the final standards; and (3) move forward witn the planning and activities necessary to implement remedial actions that comply with the EPA standards when they are finalized.

In order to assess the impacts of the proposed EPA standards, this report summarizes the proposed EPA standards in Section 2.0. The next three sections (3.0 through 5.0) assess the impacts of the three parts of th FPA standards: Subpart A (Section 3.0) considers disposal si tes; Subpart B (Secivill 4.0) is concerned with restoration at processing sites; and Subpart C (Section 5.0) addresses supplemental standards. Section 6.0 integrates previous sections into a recommendations section. Section 7.0 contains the DOE responses to questions posed by the EPA in the preamble to the proposed standards. 


\subsection{OVERVIEW OF PROPOSED STANDARDS}

The 1983 standards for the Title I (inactive) uranium mill tailings sites required:

C A remedial action design effective for up to 1000 years, to the extent reasonably achievatle and, in any case, for at least 200 years, that limits radon emissions and dispersal of tailings by man and natural processes.

- Cleanup of land and vicinity properties to reduce indoor radon and gamma radiation.

- Disposal and cleanup to meet qualitative groundwater guidance on a case. by-case basis.

On September 3, 1985, the United States Tenth Circuit Court of Appeals set aside the EPA water protection standards for Title 1, 40 CFR Part 192.20(a) (2)(3). The water protection standards were remanded to the EPA for further conside ation because the water standards promulgated by the FPA (January 5, 1983) were not of general application, as required by the UMTRCA.

In response to the Courts' remand, the newiy proposed EPA groundwater standards involve:

- Protection of human heaith and the envirorment.

- Consideration of radiological and nonradiological hazards.

- Consistency with the requirements of RCRA, as amended.

- General standards applicable to all UMTRA Project sites (i.e., not sitespecific as was the case for the remanded standards).

The se items are discussed below.

Subpart A (40 CFR Part 192.U1-192.02) consists of the requirements for control of potential contaminant releases to the groundwater at disposal sites. It incorporates the followirig:

- RCRA list of hazardous constituents (40 CFR Part 264.93).

- RCRA Maximum Concentration Limits (MCLs) (40 CFR Part 264.94), background limits, or ACLs. The establishment of ACLs must be concurred in by the MRC, be as low as reasonably achievable (ALARA), and satisfy the water-quality protection considerations stipulated in 40 CFR 264.94 (b).

- RCRA point of compliance (40 CFR Part 264.95).

- Four hazardous constituerits (molybdenum, radium, uranium, and nitrate) and associated MCLs are added to the list of water standards in 40 CFR 261. Appendix 8. (Note: an MCL for an additional constituent, gross alpha, is included separately and without discussion in Subpart A, Table A.) 
- A liner or equivalent beneath the disposal site if tailings contain excess water (40 CFR Part 192.20).

- Monitoring during a post-remedial action period to verify design performance.

- Corrective action to be initiated within 18 months after post-disposal monitoring indicates or projects an exceedance of the applicable concentration limits.

Subpart B (40 CFR Part 192.11-192.12) lists the standards applicable for remediating contaminated groundwater. It incorporates:

- Cleanup of the listed groundwater constituents to levels specified in Subpart A.

- Extension of the remedial period to allow for natural flushing if:

- The groundwater is not, and is not projected to be, a public drinking water source, and

- Institutional controls will effectively protect health and satisty other beneficial uses, and

- Concentration limits will be met in less than 100 years.

Subpart C (40 CFR Part 192.20-192.22) addresses supplemental standards applicable to Subparts $A$ and $B$. The supplemental standards provide for alternative actions which come as close to the standards "as reasonable under the circumstances." NRC concurrence in the application of supplemental standards is required. The supplemental standards may be applied if protection of human heal th and the environment is assured (4U CFR Part 192.22(d)) and:

- The proposed action would cause more environmental harm than it would prevent (40 CFR Part 1.92.21(b)), or

- Restoration is technically impracticable from an engineering perspective (40 CFR Part 192.21(f)), or

- The groundwater is Class III (40 CFR Part 192.21(g)).

Definitions in the standards include:

Remedial period: the period of time beginning March 7, 1983, and ending wi th the completion of requirements specified under a remedial action plan.

Remedial Action Plan: a written plan for specific site that incorporates the results of site characterization studies, environmental assessments or impact statements, and engineering assessments into a plan for disposal and cleanup that satisfies the requirements of subparts $A$ and $B$.

Post-disposal period: the period of time beginning immediately after the completion of the requirements of Subpart $A$ and ending at completion of the nonitoring requirements established under 40 CFR $192.02(b)$. 
Groundwater: subsurface water within a zone in which substantially all the voids are filled with water under pressure equal to or greater than that of the atmosphere.

Class III groundwater: groundwater that is not a current or potential source of drinking water because (1) the concentration of total dissolved solids is in excess of $10,000 \mathrm{mg} / \mathrm{l}$; (2) widespread, ambient contamination not due to activities involving residual radioactive materials from a designated processing site exists that cannot be cleaned up using treatment methods reasonably employed in public water-supply systems; or (3) the quantity of water available is less than 150 gallons per day.

Point of compliance: for processing sites from which tailings have been relocated, the point of compliance $(P O C)$ is any point where contamination is found in the groundwater.

Although not included as new definitions in the standards, the following are pertinent to understanding and assessing the impact of the standards:

Point of compliance: for disposal sites (40 CFR Part 264.95) it is a vertical surface located at the hydraulically downgradient limit of the waste management area that extends down into the uppermost aquifer underlying the regulated units. The waste management area is the limit projected in the horizontal plane of the area on which waste will be placed during the active life of a regulated unit and includes horizontal space taken up by any liner, dike, or other barrier designed to contain waste in a regulated unit.

Practicable: it is noted in the preamble to the proposed standards that "the word practicable is not identical in meaning to the word practical. As usea here, the former means able to be put into practice and the latter means cost-effective."

The standards may also be applicable or relevant and appropriate requirements for remedial actions at other DOE sites and facilities. Thus, the impacts or these standards when finalized would be much broader than currentiy envisioned by the EPA. 


\subsection{ASSESSMENT OF IMPACT OF DISPOSAL SITE STANDARDS}

\subsection{INTRODUCTION}

Subpart $A$ of the proposed EPA standards addresses the requirements for groundwater quality applicable to disposal sites. This section discusses the impact of Subpart A on the design of remedial actions for tailings stabilized on site or tailings relocated from a processing site to a hew disposal site. (Subsequent sections of this report address the impact of the standards on existing contaminants at and around processing sites and the applicability of supplemental standards.)

\subsection{DESIGN LIFE}

On the basis of the longevity standard, a remedial action design for UMTRCA Title I sites must be effective for 1000 years, to the extent reasonably achievable, and, at any rate, for at least 200 years. The design must limit radon emissions and prevent dispersal of the tailings by man and natural processes. As applied to date on the UMTRA Project, the se longevity requirements have led to disposal designs that use only natural materials and wich incorporate (or consider) the subsurface zone as an integral part of the natural disposal system. In meeting the specified design life, all practical measures must be taken to achieve remedial actions effective for that period. Only if detailed studies demonstrate that the 1000-year requirement cannot be met is it permissible to consider a lesser design life. It is not permissible simply to say that the design will be effective for at least 200 years and therefore is satisfactory.

The proposed EPA groundwater standards have their principal genesis in RCRA. The standards incorporate the RCRA philosophy of complete contaiment. These sites typically incorporate double, synthetic liners and leachate collection system; as part of the design philosophy of preventing seepage from the encapsulated waste from migrating to the subsurface environment. The proposed standards define the point of compliance (POC) on the basis of the RCRA design life and contaiment philosophy.

For RCRA sites, post-closure performance is addressed for approximateIy 30 years. This period may be extended indefinitely if exceedances are detected. The differences between RCRA sites and UMTRA Project sites reflect different technological choices for carrying out similar philosophical objectives, namely to minimize releases for as long as reasonably achievable.

These different technological choices or philosophical approaches to design, and degree and method of containment of the wastes have led to wat the DOE believes are conflicting and mutually inconsistent requirements with respect to imolementing longevity requirements and meeting the proposed groundwater standards. To better appreciate the origin of the conficts and the significant differences between the UMTRA Project remedia) actions and those of other programs, the basic designs are discussed below. 


\subsubsection{UMTRA Project piles}

Figure 3.1 shows typical UMTRA Project pile. The tailings pile is shaped and covered with an infiltration barrier and an erosion barrier. (The infiltration barrier also serves as a radon barrier to prevent emanation of radon gas from the pile.) As shown in Figure 3.2, rain and snownelt fall on the pile and pass through the rock erosion barrier. Most of this water flows later. ally off the pile through the filter above the infiltration barri.. er: however, some water seeps into and through the infiltration barrier and through the tallings. At some piles vegetation is established (or could be established) in soll or soil/rocik matrix layer that could be placed on or in lieu of the rock layer. In this case, evapotranspiration may remove water.

As shown in Figure 3.2, the design includes not only the tailings pile and the cover, but the subsurface environment (i.e., soils, rocks, and groundwater). This environment is an integral part of the remedial action scheme and an essential component in dealing with the contaminants in the tailings.

In this controlled release design, water seeps from the base of the pile and enters the unsaturated soils and rocks beneath the plle. In the unsaturated zone, the seepage flows essentially vertically downward under gravity. (Local hydrostratigraphic and structural features may interrupt vertical flow.) As seefage from the pile flows through the unsaturated soils and rocks, chaiges in seepage chemistry will occur as a result of chemical interaction between the seepage and the constituents of the soils and rocks.

Once the seepage encounters the water table, mixing of the groundwater and the seepage begins. As the groundwater flow direction is generally horizontal, contaminants in the seepage move out from beneath the plle (i.e., beyond a POC at the edge of the pile). As the mixed groundwater and seepage flows away from the pile, further mixing, attenuation, and dispersion occur and the chemistry of the groundwater changes. Thus, contaminant concentrations reduce with increasing flow distance from the pile.

The approach of including the subsurface environment within the remedial action scheme is a direct result of the EPA standards design life of 1000 years (to the extent reasonably achievable). Only natural materials and systems have the properties and characteristics essential to such a long design life.

\subsubsection{RCRA and other disposal designs}

RCRA sites involve systems to totally isolate wastes from the environment (Figure 3.3). As compared to the UMTRA Project designs, RCRA sites do not consider the subsurface environment as part of the contaiment. Rather, the site is designed, using syntnetic materials as covers, double liners, and drains, to preclude all seepage from the wastes from entering the subsurface environment. 


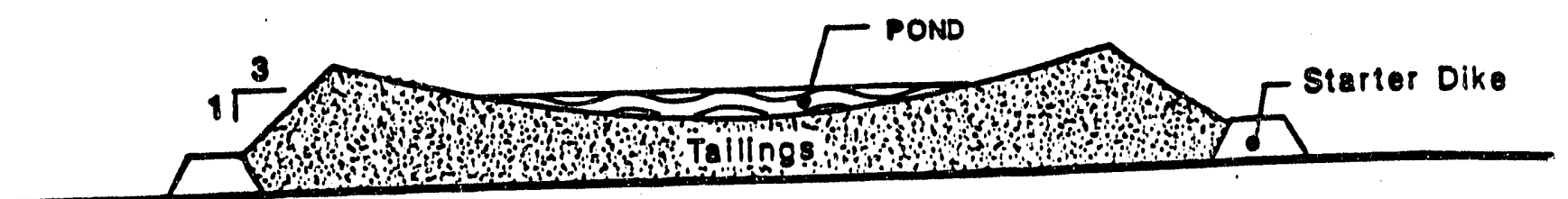

A

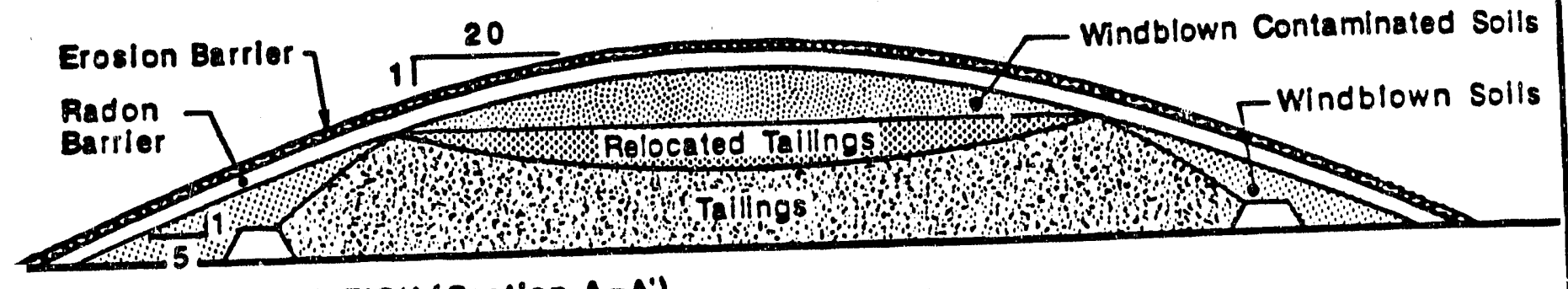

AFter ReClamation (section A-A')

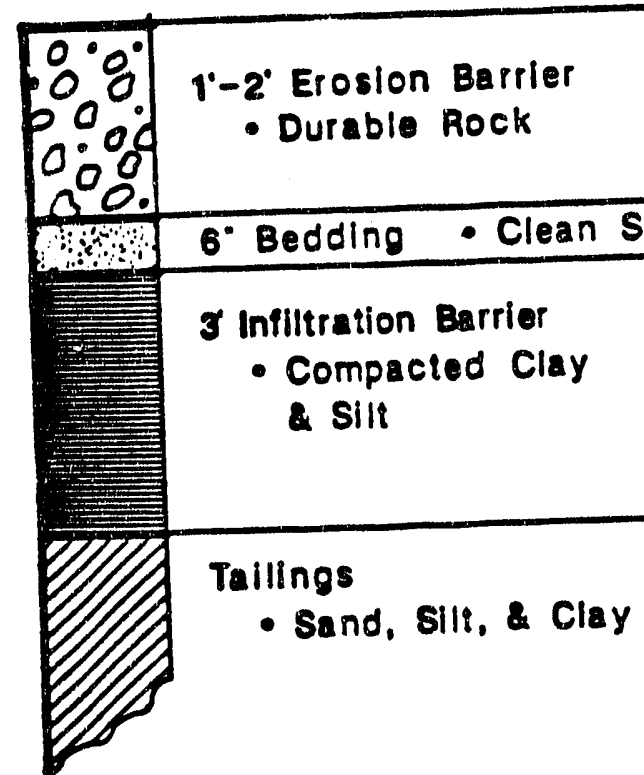

COVER DETAIL

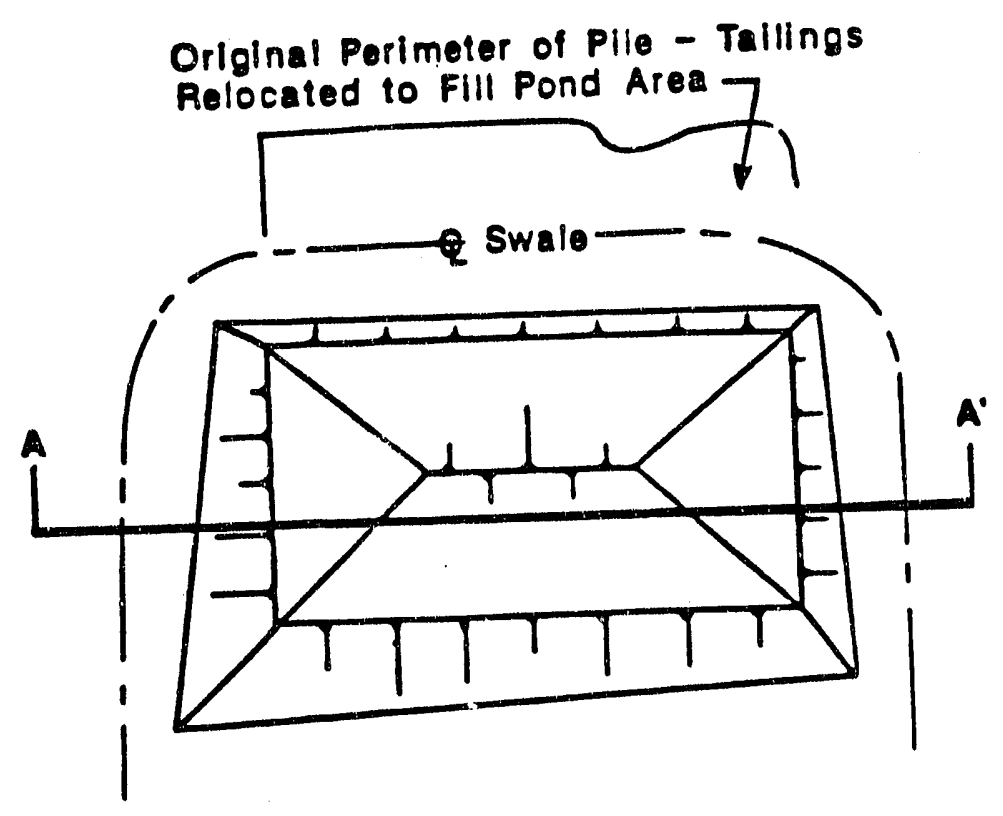

plan layout

F1gum: 3.1 Typlcal corrR Project plle layout 


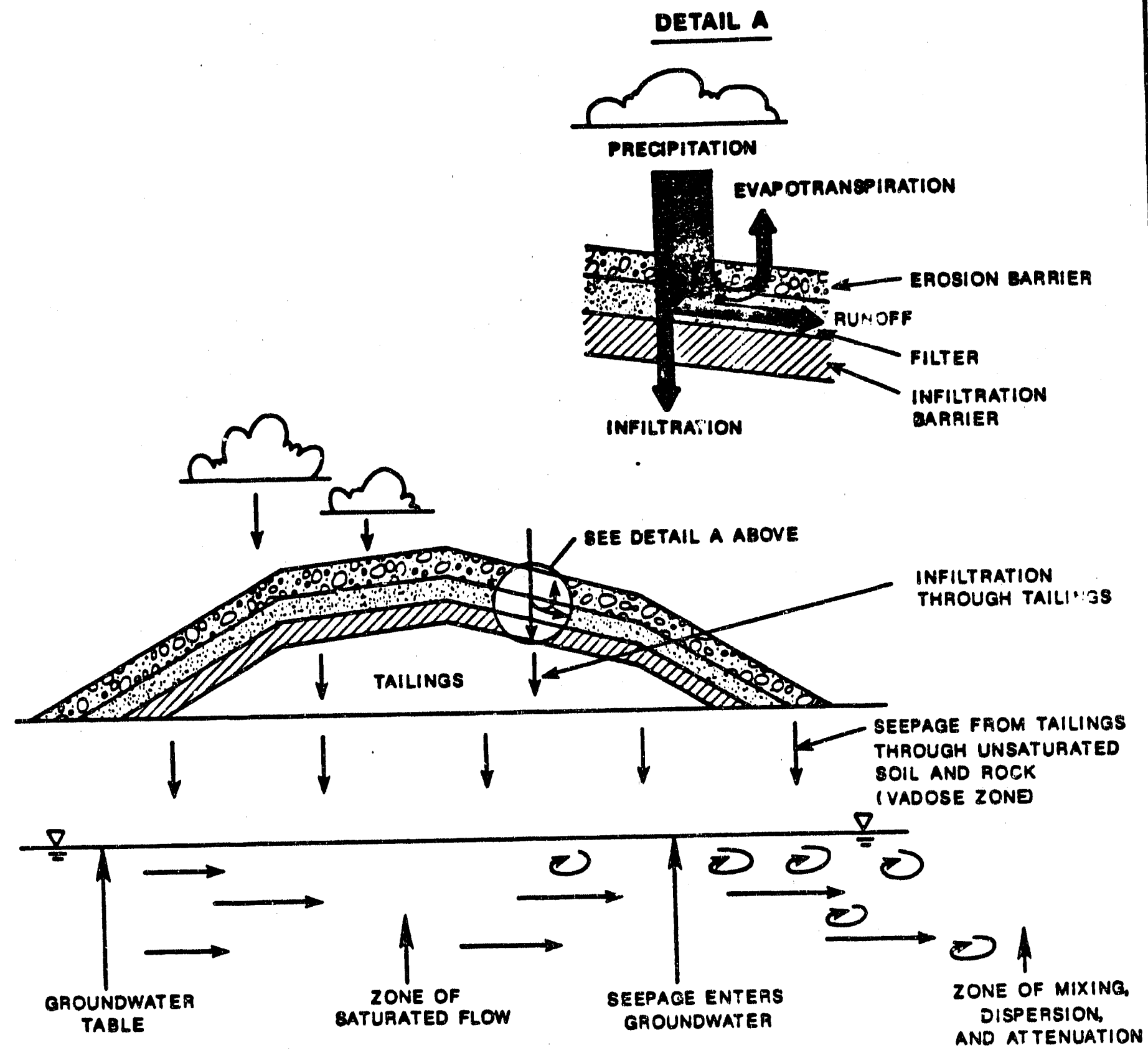

Figure 3.2 UnTRA project pile reanedial action infiltration and groundwater interaction 


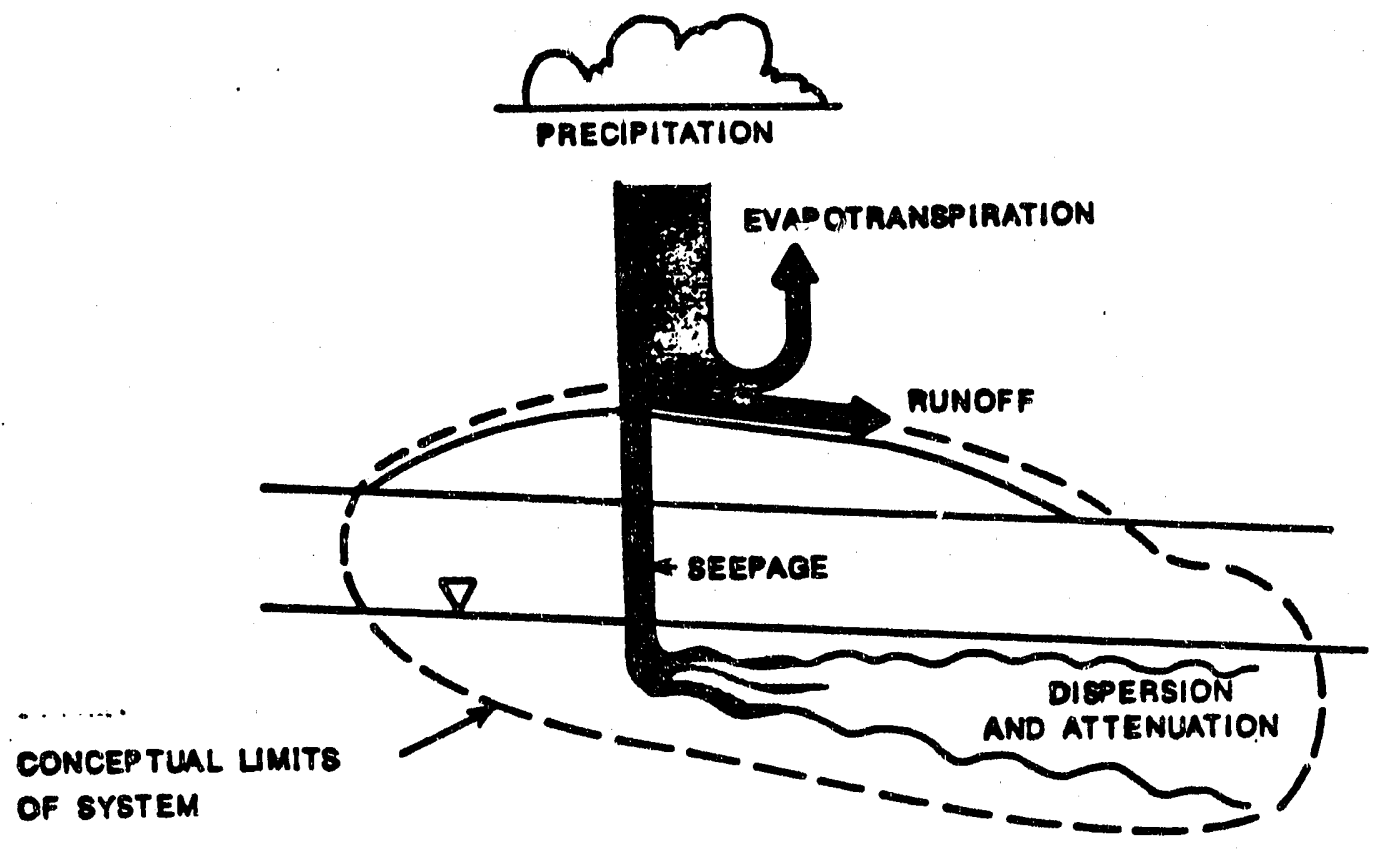

UMTRA PROJECT DISPOSAL FACILITY

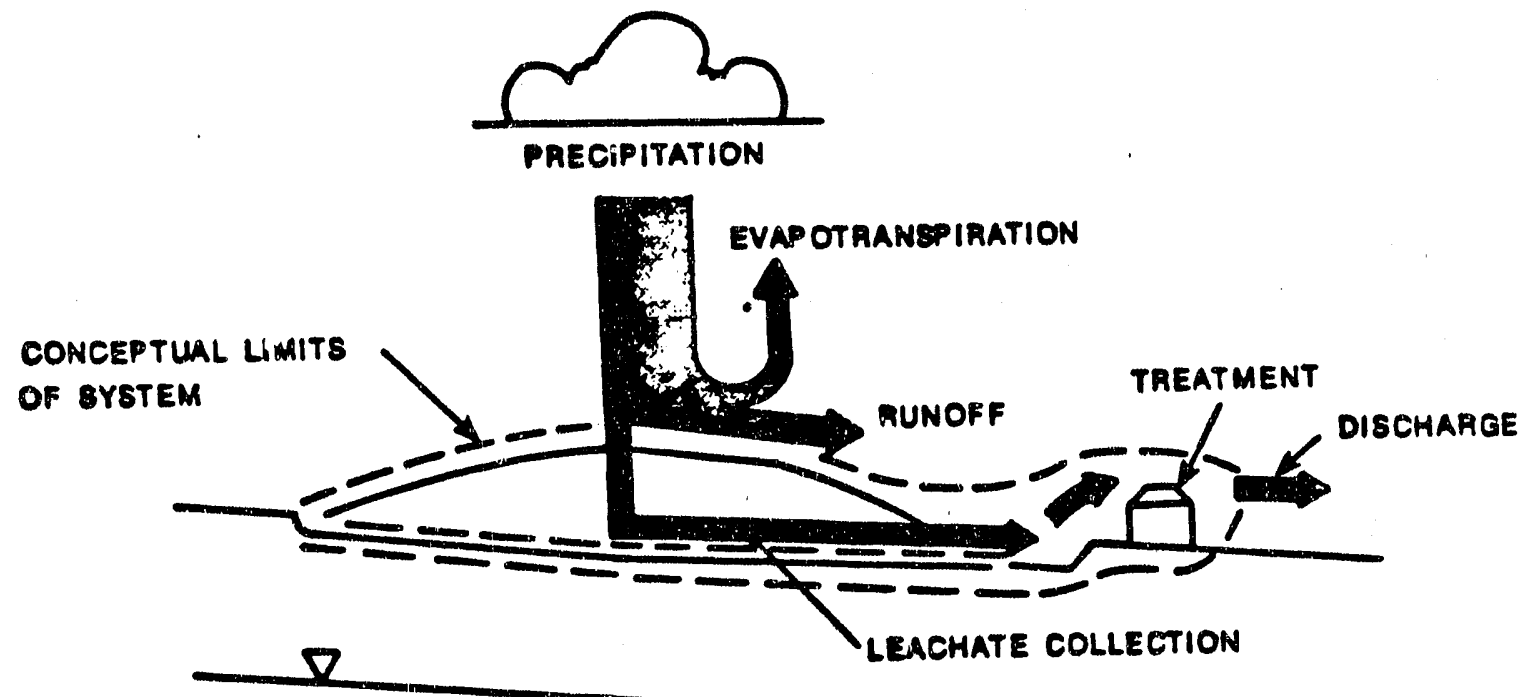

RCRA CONTAINMENT CELL

Figure 3.3 Comparison of limits and precipitation

diversion of LNTRA Project and RCRA facilities 
Because of the permissibility of using synthetic liners and leachate treatment systems, it is possible to isolate seepage wastes from the subsurface environment. For the reasons discussed above, this is not acceptable at UMTRA Project sites.

Synthetic materials incorporated into RCRA sites probably will not last for 200 to 1000 years. They are included, however, because they contribute to the regulatory aim and objective of minimizing releases for as long as is reasonably achievable. Current technological experience is that such synthetic material will last for at least 30 years and possibly longer. It has not been possible to predict their performance over 200 and more years.

Mixed wastes (i.e., hazardous and radioactive source special nuclear, or byproduct material) have the radioactive component in common with UMTRA Project wastes. Based on recent EPA and MRC guidance, the techniques and methods used in the design of a mixed waste site result in a design life that is much less than that required by the EPA standards on the UMTRA Project. The design may incorporate provisions for human custodial care and maintenance.

Figure 3.4 shows a conceptual design proposed jointly by the EPA and the NRC for low-level mixed waste. This proposed design also specifically incorporates synthetic materials. Again, the use of such materials is an integral part of the aim of minimizing releases for as long as is reasonably achievable. Use of synthetic materials, which have not been demonstrated to last for 200 and more years, is possible in low-level mixed waste sites, because there is no specific design life requirement for 1000 years as exists for UMTRA Project sites.

\subsubsection{Application to the UMTRA Project}

To comply with the proposed standards, the UMTRA Project longevity standards would have to be relaxed to enable synthetic covers, liners, and leachate collection systems to be incorporated into UMTRA Project remedial actions. In addition, it would be necessary to relax the UMTRA Project requirement for minimum postclosure maintenance before the concept of intercepting the leachate for treatment can be applied on the UMTRA Project.

It can be argued that as UMTRA Project wastes were placed on very low-permeability liners and provided with underdrains or leachate collection systems, the leachate could be brought to evaporation ponds that will operate with minimum or no human intervention. To prevent inadvertent human access to the leachate, the leachate could drain into rock-filled, lined sumps or toe aprons from which some evaporation or flow to the surface could occur. Evaporites would collect in the rocks. However, it may be difficult to argue that such an approach could protect the environment and ensure human health and safety for periods extending to 1000 years. 

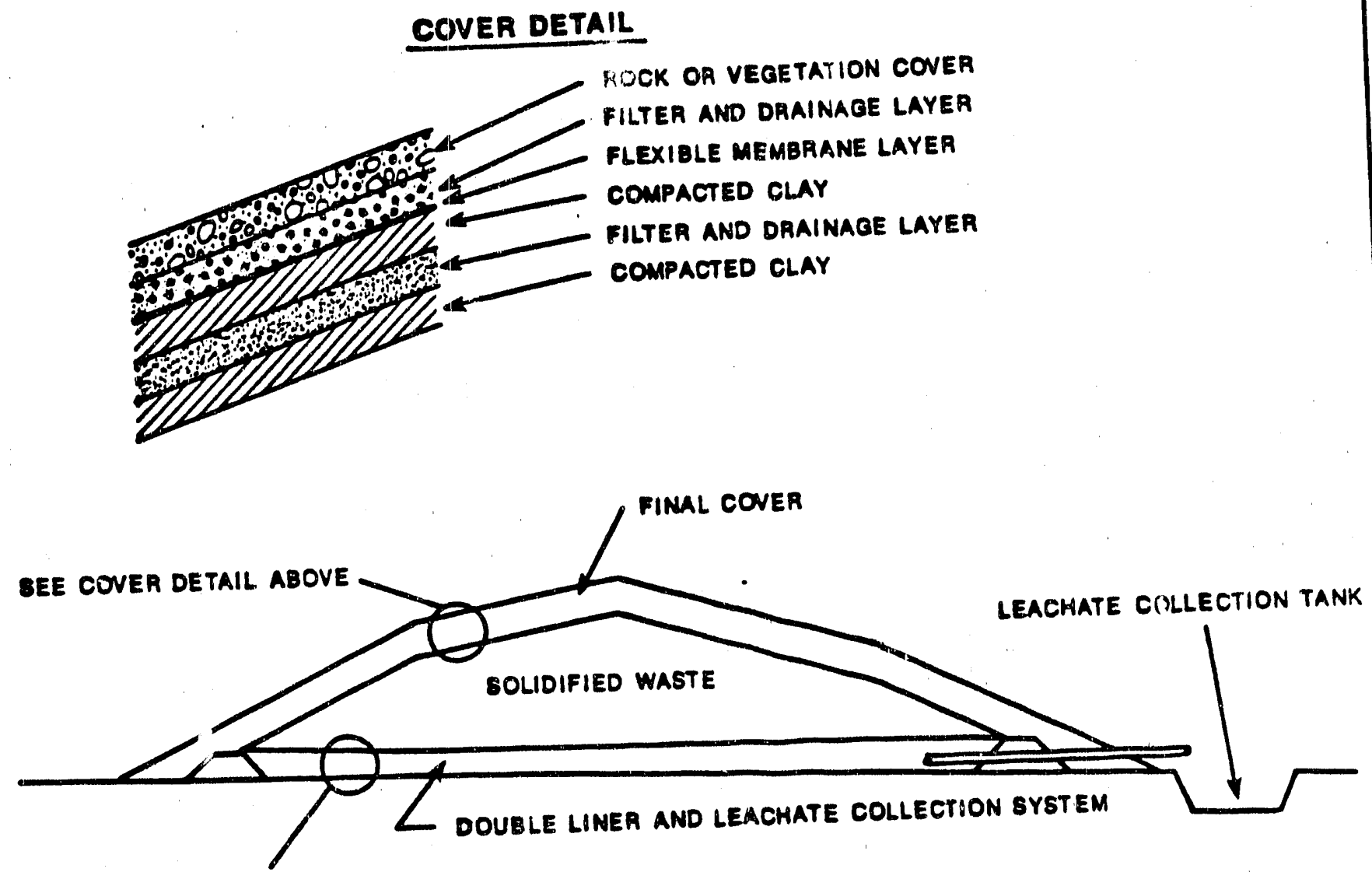

BEE LINER DETAIL BELOW

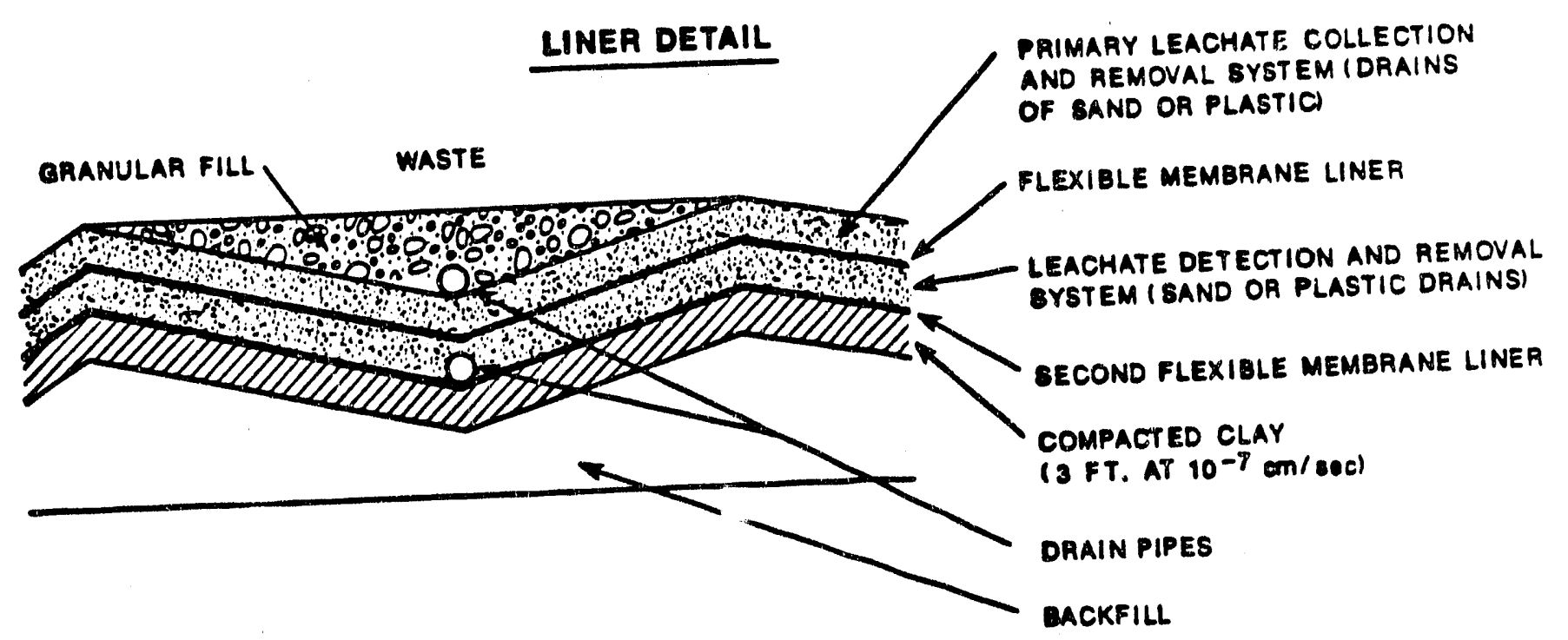

F1gure 3.4 Typical af xed low-ievel waste cell 


\subsection{PILE DESIGN CONSTRAINTS}

Whether a tallings pile is relocated to a new site or stabilized on site, the prime concern is the design and construction of a repository that minimizes infiltration and percolation such that concentration limits of constituents are not exceeded beyond the point of compliance (defined in 40 CFR Part 264.95).

Because of the specified design life requirement to control the tailings and contaminated materials for 1000 years, only natural materials have been used in the construction of the stabilized pile. To the extent practicable, low-permeability materials are placed and compacted over thie contaminated materials. However, as discussed in more detall in the Subsecticn below on liners and covers, the use of natural materials makes it impossible to place a cover that totally excludes the passage of water through the tailings. Hence, there is an inevitable conflict between the requirement for disposal site longevity and the need to prevent passage of water through the repository to meet the standards at the point of compliance. Some water will pass through the repository regardless of its design.

Given that some seepage will occur, appropriate disposal site selection for relocated piles is one means of limiting the likelihood of an exceedance of the proposed EPA groundwater standards. Sites having one or more of the following characteristics may be suitable:

- A deep water table.

- Class III groundwater beneath the pile.

- A natural, continuous, thick clay or shale layer above useable groundwater.

- Cover materials having very low hydraulic conductivity.

However, assuming no attenuation in the vadose zone, once the seepage from the pile contacts groundwater, the proposed standards cannot be achieved at the edge of the pile for many sites. Instead, a finite distance from the pile edge is required before mixing, dispersion, and attenuation bring the resulting concentrations to below proposed EPA limits. For example, computer modeling of the final cover designs at UMTRA Project disposal sites indicates that the concentration limits of Subpart A would be met at distances from 100 to 1500 feet of the pile edge. These designs would require cover hydraulic conductivities as low as $10^{-7}$ or even $10^{-8} \mathrm{~cm} / \mathrm{s}$.

The proposed EPA standards, in effect, demand a technical impracticability in the design of many tailings piles. Because of the impracticability of achieving the standards at the edge of the pile, a variance (probably in the form of ACLs) would be required at many UMTRA Project sites. However, it is unreasonable to establish standards so strict that variances from the standards are necessary in the majority of cases. One potential solution to this dilemma is to define the point of comoliance to be a 
reasonable distance downgradient of the edge of the stabilized pile and that includes the intervening geology as part of the waste managerrent area. Accordingly, the DOE requests a redefinition of the POC. This proposed redefinition can provide for the protection of human health and the environment, and, in addition, makes possible the adoption and use of practical engireering solutions. Section 6.0 provides additional information on this issue. In addition, the DOE will provide the modeling results and supporting documentation to the EPA for review.

\subsection{LINERS AND COVERS}

The EPA in Question 1 (see Section 7.0) asks if liners should always be required at relocated tailings piles. The DOE does not consider liners mandatory for all relocated tailings piles, although they may be appropriate in some cases based on technical need. The following discussion provides:

- Additional supporting arguments for the DOE opinion; and

- An expanded description of current UMTRA Project cover design practice and the approach that the DOE considers practical, reasonable, and in accord with existing standards.

Liners fall into two categories: (1) natural; ana (2) synthetic. Natural liners are composed of soils such as clays, or sandy soils which may be amended with a clay mineral such as bentonite, or an additive such as lime or fly ash. Synthetic liners are composed of plastics such as high density polyethylene, PVC hypalon, or other plastics.

Since the UMTRA Project must design for 1000 years, synthetic liners are not a practicable alternative since the longevity of synthetic liners has not been sufficiently demonstrated.

The need for natural liners must be evaluated on a site-specific basis considering the depth to the water table, permeability of the foundation materials, quality of the water below the tailings pile, and rate and amount of infiltration through the cover system. The most important factor in evaluating the need for a liner is the cover system. If a cover system limits infiltration and promotes runoff, then there would be no need to install a liner to prevent percolation into the groundwater.

Cover systems on the UMTRA Project normally consist of a layered system wich starts at the tailings with windblown or lesser contaminated material varying in thickness from two to 15 feet. This material is usualIy a sandy material wich acts as a capillary break, restricting the downward movement of water. The radon barrier is placed on top of this material and is usually three feet thick; however, the thickness may vary from 1.5 to seven feet. The radon barrier material is usually a sandy clay with a hydraulic conductivity of approximately $10^{\circ} \mathrm{cm} / \mathrm{s}$. The radon barrier also acts as the infiltration barrier. When a sandy clay of sufficlently low permeability is not available, soll amended with bentonite is used to lower the permeability and radon diffusion coefficient. 
On top of the radon/infiltration barrier is a six-inch bedding/filter layer. This material is usually a coarse, and and gravel which serves two purposes: (d) it is a bedding for the overlying rock erosion barrier; and (2) it acts to prevent erosion of the radon/infiltration barrier due to flow of water on top of the radon barrier. The hydraulic conductivity of this layer varies from site to site, but is usually in the range of $10^{-1}$ to $10^{-3} \mathrm{~cm} / \mathrm{s}$.

The last layer of the cover system is a one-foot-thick rock erosion protection layer that: (1) protects underlying layers from erosion: (2) precludes intrusion by burrowing animals; and (3) promotes drainage and reduces evaporation (therefore precluding drying and cracking of the radon/infiltration Darrier).

A major advantage of using a cover system rather than a liner is to avoid a "bathtub" effect. A "bathtub" occurs when the permeability of a liner is the same or lower than that of the cover. As water percolates through the pile, the water ponds and saturates the liner, which may cause unwanted drainage to the land surface.

\subsection{ALTERNATIVE PILE DESIGN ENHANCEMENTS}

This section discusses design and construction measures that may be taken to reduce seepage from a pile, reduce groundwater impacts, and enhance the likelihood of meeting the proposed EPA groundwater standards.

If a tailings pile is to be stabilized in place (SIP), the following steps could reduce infiltration, leachate production, and ultimately groundwater contamination:

- Amend the radon/infiltration barrier soll with bentonite to reduce its permeability and thereby reduce percolation. There is a limit to which the permeability fan be reduced. In particular, a hydraulic conductivity of $10^{-7} \mathrm{~cm} / \mathrm{s}$ is practicable; however, lesser hydraulic conductivities are not routinely achievable, and can be achieved only with exceptional construction care where suitable source solls are avallable.

- Compact the radon/infiltration barrier to a higher censity. This may reduce the permeability to some finite 1imit; however, costs are increased and the method is possible only if this higher density can be accomplished throughout the barrier.

o Steepen the topslopes so that runoff occurs more rapidly.

- Increase the particle size of the bedding/filter layer materials. This increases the permeability of the layer and thereby reduces the time required for runoff to occur.

- Add additional layers on top of the erosion protection so that the tallings pile can be revegetated. This would reduce infiltration due to evapotranspiration. Vegetation has been used and will be 
used as part of multi-layer cover systems at selected UMTRA Project sites (Canonsburg, Lakeview, Falls City). However, in 1000 years, vegetation could die or the soll in which it grows could erode.

- Use soil/rock matrix covers. To construct such a layer, a rock matrix with a particle size gradation that is resistant to erosion by runoff from the design precipitation is placed. Soil is vibrated or otherwise worked into the voids of the rock. Vegetation is established in the soil and this may enhance evapotranspiration. Practical experience indicates that the permeability of such systems is relatively high: significant infiltration may occur through the soil/rock matrix and hence through the infiltration barrier. It is unlikely that soil/rock layers could be constructed to be a significant impediment to infiltration (hence to act as a means of meeting the proposed EPA groundwater standards).

- Place man-made, low-permeability liners within the infiltration barrier. For example, synthetic liners of high density polyethylene or asphait could be incorporated into the infiltration barrier. The longevity of synthetic liners has not been demonstrated; it is questionable that they could meet UMTRA Project design standards. An asphalt layer, to be effective, would have a high bitumen content and would be thick. Creep of such a viscous layer could occur down the slopes of a pile, causing it to fall to meet longevity standards. Therefore, asphait, if it is shown to be useful, may be limited to the tops of piles.

- Incorporate a capillary break into the cover. A capillary break is usualiy a sand layer placed beneath a lower permeability soil. When the moisture content of the soil is relatively low, the larger pores of the sand limit seepage from the soil. The water will remain in the soil reservoir until removed by evapotranspiration. If the soil becomes saturated, the capillary effect is broken and water moves into the sand. The effectiveness of a capillary break in an UMTRA Project cover thus depends on the presence of vegetation and precludes saturation of the soil. To rely on these breaks as the sole means of complying with the proposed EPA standaros is not considered feasible.

In addition to the above design considerations, if a tailings pile is to be relocated, the following could be done:

- Construct low-permeability, geochemical layer at the base of the pile. This could be a clay, hydrated 7 ime, organic material, or artificial polymer that would act to precipitate or adsorb contamimants. Such layers are being evaluated for selected UMTRA Project sites. To date, there is minimal experience with the long-term erfectiveness of such components.

- Promote flushing of the tailings. In concept, the following could be done: (1) place a liner on the foundation soils; (2) construct drains; (3) compact tailings into place; (4) supply copious quantities of water to the top of the pile; (5) collect and treat the 
seepage from the pile. In practice, there is very little practical experience with such systems. The disadvantages are: significant quantities of radioactive hazardous waste sludge from the treatment plan would have to be disposed of: it is questionable if such scheme could be completed within the UMTRA Project timeframe; the long-term efficacy of such a system is not proven.

- Above-ground disposal. UMTRA Project sites could be placed on very low-permeability liners and provided with underdrains or leachate collection systems; the leachate could be brought to evaporation ponds that will operate with minimum or no human intervention. However, it may be difficult to argue that such an approach could protect the enviroment and ensure human health and safety for periods extending to 1000 years.

Repeated evaluations have shown that the amount of water that can percolate tnrough the cover to become leachate is sensitive primarily to the hyoraulic conductivity of the infiltration barrier, and is relatively insensitive to other factors such as slope of the pile surface, permeability of the overlying filter layer, and thickness of the low-permeability layer or filter layer. Many of the concepts summarized above are expected similarly to be less effective than infiltration barrier permeability in reducing leachate. Furthermore, most are yet to be proven in actual field application. However, the concepts, and others that may be identified, will continue to be evaluated on a case-by-case basis.

\subsection{APPLICATION OF ACLS TO DISPOSAL FACILITY DESIGN}

If the EPA does not accept the changes to the proposed standards as recommended by the $D O E$, it is anticipated that significant reliance will have to be placed on ACLs. Figure 3.5 shows the logic orocess that would be employed as necessary to invoke ACLs. The DOE considers that, in the absence of significant changes in the standards as proposed, the procedure shown in Figure 3.5 would have to be adopted at the majority of UMTRA Project disposal sites. While this approach is conceivable, and indeed probably the only practicable way of meeting the proposed EPA standards, the DOE believes that it is unreasonable to establish standards so strict that variances from them are necessary ill the majority of cases.

Furthermore, the DOE notes that the process of establishing appropriate ACLs will involve considerable discussion with the NRC (and possibly the affected states and tribes). It is possible that consensus on appropriate ACLs will not be attalnable or will be so delayed as to negatively impact implementation of remedial action. In addition, there may be states with RCRA permitting authority that have a non-degradation standard that may preclude the use of ACLs.

3.7 EXAMPLES OF TECHNICAL IMPRACTICABILITY FOR DISPOSAL SITE REMEDIAL ACTION DESIGNS

Section 5.0 discusses the concept and philosophy of technical impracticadility; this section focuses on examples. Pursuant to the preceding 


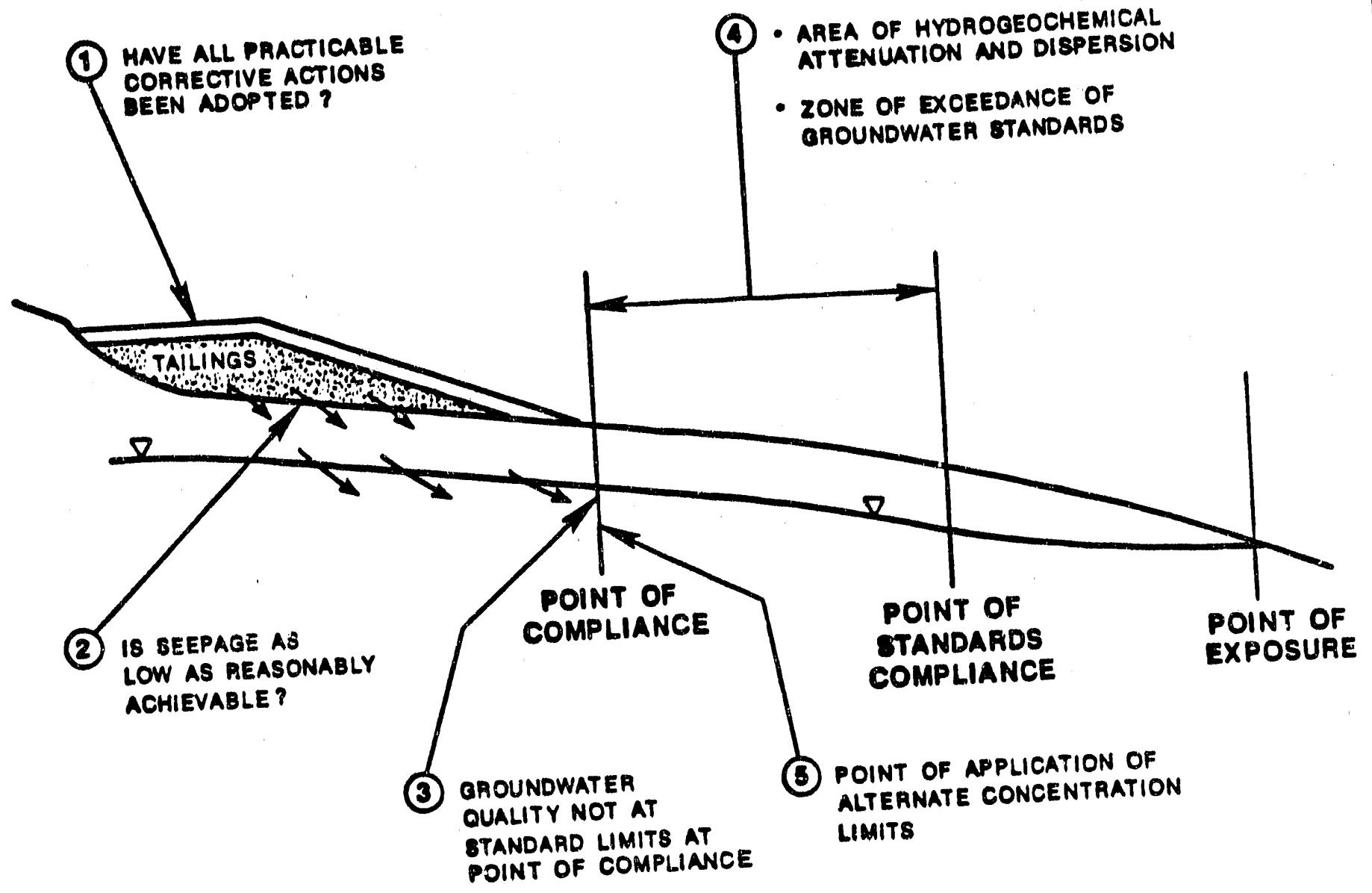

Figure 3.5 ACL application sequence 
discission, it is reasonable to conclude that the following are possible cases of tachnical impracticadility that may arise in the design and construction of remedial actions at disposal sites:

- Construct an infiltration barrier of natural materials with an assure 9 long-term hydraulic conductivity of less than approximateiy $10^{-9} \mathrm{~cm} / \mathrm{s}$.

- Construct a homogenous soil cover that will support vegetation and that has a hydraulic conductivity significantly less than $10^{-3}$ $\mathrm{cm} / \mathrm{s}$.

- Incorporate synthetic materials with an assured performance 11 fis of 200 years.

- Preclude, using only natural materlals, all infiltratio: to the tailings.

- Prevent seepage from entering the subsurface environment without using liners and leachate collection systems.

- Provide leachate collections with assured performance for 200 years.

- Provide leachate disposal systems that function without human intervention and do not negatively impact the environment.

$3.8 \cos T$

Design and construction cost impacts for Subpart $A$ have not been estimated at this time as the proposed standards are anticipated to require a unique technical approach for each disposal site. A secondary cost would be incurred if remediated sites needed to be retroactively enhanced to meet the proposed standards. No cost estimate to accomplish such a retrofit is available. 


\subsection{ASSESSMENT OF IMPACTS OF GROUNDWATER RESTORATION}

Groundwater quality generally does not meet the proposed EPA maximum concentration limits (MCLS) at sites where tailings were deposited. Cleanup will generally be the required course of action at these processing sites.

This section of the report discusses the costs and implications of aquifer restoration at and around processinc sites.

\subsection{AQUIFER RESTORATION}

Partial or complete aquifer restoration is required by the proposed EPA standards if: groundwater does not meet the proposed MCLs, background concentrations, or accepted ACLs; natural processes will not clean up the aquifer in 100 years; or application of supplemental standards is not appropriate. Partial aquifer restoration involves active cleanup to a condition where continued natural processes will bring the groundwater quality into compliance with appropriate concentration limits within 100 years of the start of groundwater remedial actions.

During active or natural (passive) groundwater restoration, the DOE advocates implementation of institutional controls. Institutional controls are governmental actions wich prohibit or control the use of contaminated groundwater. If it is neither feasible nor legally possible for a state or tribe to prohibit or control the use of contaminated groundwater, the DOE could authorize the state or tribe to acquire land and groundwater rights as a part of the remedial action cost.

A decision to apply institutional controls and the period of the control will be based on site-specific conditions and concerns. The DOE and the affected state or tribe will decide (with MRC concurrence) on the necessity for and nature of institutional controls required to protect human heialth and the envirorment.

\subsection{PRELIMINARY AQUIFER RESTORATION MODELLING}

As a first step toward estimating the total project groundwater restoration costs, the conditions, requirements, and aquifer restoration costs at five sites were considered. These sites were: Gunnison, colorado; Riverton, Wyoming; Lakeview, Oregon; Tuba City, Arizona; and Falls City, Texas. For each site, representative conceptual groundwater restoration schemes were proposed, evaluated, and base costs were estimated in 1987 dollars.

The site-specific aquifer restoration base costs were developed in a four step process:

- Development of a conceptual model of contaminant distributions and hydrological and geochemical properties, boundaries, and conditions. 
- Application of the Random Walk Algorithm (IIlinois State Water Survey, 1981) to calibrate the model against the distribution of field-measured groundwater quality.

- Application of the Random Walk Algorithm to simulate various aquifer restoration scenarios to determine an efficient scenario(s) and associated design parameters.

- Estimation of aquifer restoration costs based on the simulated scenarios, design parameters, and assumptions.

The development of the conceptual model required a determination and application of key hydrological and geochemical parameters that control the movement of contaminants, and the distribution of the source of these contaminants as a function of time. The contaminants that were considered are those with concentrations greater than the proposed MCL and greater than the background concentration in the area hydraulically downgradient of the source area (f.e., the pile). The spatial distributions of these contaminants were idealized so that the solution of the solute transport equation would fit the contaminant distributions. In this case, idealizing the contaminant distributions meant assuming that the plume was axisymetric. The final step in developing the conceptual model was to determine appropriate values or ranges of values for the various input parameters. The input parameters were the direction and rate of groundwater flow, the aquifer thickness, hydraulic conouctivity, storativity, porosity, the temporal distribution and the location of the contaminant source, the range of longitudinal dispersivity, the range of transverse dispersivity, the range of the retardation coefficient, and the distance to the groundwater discharge boundary.

The Random Walk Algorithm simulates the movement of a contaminant mass as the movement of a specified number of particles that represent the contaminant mass. During any given time step, the movement of each particle is influenced by the direction and magnitude of the velocity, normal distributions around the magnitude of the two dispersivity values, and the location and strength of extraction wells or trenches and injection wells.

The parameter values and ranges and the initial and boundary conditions developed from the conceptual model were applied in the calibration procedure. In the calibration, the parameter values were kept consiant except for the longitudinal and transverse dispersivities and the retardation coeficicients. These values were varied to find the set of parameter values that provided the best correlation between observed concentrations and calculated concentrations. These values were varied until an "adequate" calibration was produced.

The treatment options (see Table 4.1) simulated for aquifer restoration included:

Treatment Option 1: Extract until MCLs are satisfied, treat if necessary, and di scharge. 
Table 4.1 Aquifer restoratio.r description and duration

\begin{tabular}{|c|c|c|c|}
\hline Site & $\begin{array}{l}\text { Treatment } \\
\text { option }\end{array}$ & Contaminants & $\begin{array}{l}\text { Duration } \\
\text { of active } \\
\text { restoration } \\
\text { (yrs) }\end{array}$ \\
\hline Gunni son & 1 & $\begin{array}{l}\text { selenium, uranium, } \\
\text { cadmi um, nitrate }\end{array}$ & 30 \\
\hline Gunnison & 2 & $\begin{array}{l}\text { se lenium, uranium, } \\
\text { cadmium, nitrate }\end{array}$ & 6 \\
\hline Gunnison & 3 & $\begin{array}{l}\text { selenium, uranium, } \\
\text { cadmi um, nitrate }\end{array}$ & 25 \\
\hline Gunni son & 4 & $\begin{array}{l}\text { selenium, uranium, } \\
\text { cadmium, nitrate }\end{array}$ & 5 \\
\hline $\begin{array}{l}\text { Riverton } \\
\text { Rivertion } \\
\text { Riverton } \\
\text { Riverton } \\
\text { Lakeview }\end{array}$ & $\begin{array}{l}1 \\
2 \\
3 \\
4 \\
1\end{array}$ & $\begin{array}{l}\text { uranium, mo lybdenum } \\
\text { uranium, mo lybdenum } \\
\text { uranium, mo lybdenum } \\
\text { uranium, mo lybdenum } \\
\text { arsenic, cadmium, chromium } \\
\text { molybdenum, selenium }\end{array}$ & $\begin{array}{r}100 \\
24 \\
60 \\
16 \\
28\end{array}$ \\
\hline Lakeview & 2 & $\begin{array}{l}\text { arsenic, cadmium, chromium } \\
\text { molyboenum, selenium }\end{array}$ & 16 \\
\hline Tuba City & 1 & $\begin{array}{l}\text { cadmium, selenium, uranium } \\
\text { nitrate }\end{array}$ & 35 \\
\hline Tuba City & 3 & $\begin{array}{l}\text { cadmium, selenium, uranium } \\
\text { nitrate }\end{array}$ & 25 \\
\hline $\begin{array}{l}\text { Falls City } \\
\text { Falls City }\end{array}$ & $\begin{array}{l}1 \\
3\end{array}$ & $\begin{array}{l}\text { uranium, radium, molybdenum } \\
\text { uraniuni, radium, mo lybdenum }\end{array}$ & $\begin{array}{c}\text { more than } 100 \\
100\end{array}$ \\
\hline
\end{tabular}

\section{NOTES:}

a. At Gunnison, treatment of rithdrawII groundwater is necessary to meet MCLs for options 2 and 4 . Treatment is not necessary for options 1 and 3 due to mixing in the well bores of marginally-contaminated water and uncontaminated water.

b. Options 3 and 4 were not simulated for Lakeview because the contamination moves slowly with little dispersion and accounting for natural flushing does not change the estimated costs.

c. Options 2 and 4 were not simulated for Tuba city and Falls City because the contaminants are soluble and lixiviant injection is not practical. 
Treatment Option 2: Inject lixiviant (i.e., an agent which enhances mobility), extract until MCLs are satisfied, treat if necessary, and discharge.

Treatment Option 3: Extract until MCLs can be satistied with natural flushing (treat if necessary) and discharge.

Treatment Option 4: Inject lixiviant, extract until MCLs can be satisfied by natural flushing (treat if necessary) and discharge.

Options 3 and 4 also included an evaluation of a combination of active restoration ano passive restoration in ratio (active:passive) sufficient to meet the MCLs within 100 years.

For each scenario, the flow rates to well(s) and trench(es) were estimated; the duration needed to meet standards and the yields of contaminants as a function of time were calculated; and the number and location of well(s) and trench(es) were varied until the most efficient scenario was identified. The results of these aquifer restoration simulations were then used for base cost estimation.

The items factored into the base cost estimates include:

- Well or trench installation, operation, and maintenarice.

- Transportation from extraction systems to treatment plant and from treatment plant to discharge point.

- Treatment plant installation, supplies, operation, and maintenance.

- For cases with lixiviant injection, injection wells or trenches installation, operation, maintenance, and chemicals.

- Monitor well installation.

- Monitor well sampiing and chemical analyses (quarterly).

- Sampling and chemical analyses of treatment plant influent and effluent (daily).

- Supplying alternate water sources, when necessary.

- Disposal of treatment wastes from plant.

The base cost estimates include the cost-influencing assumptions that active restoration would be required at every site. The use of ACLs, supplemental standards, or passive restoration would reduce costs. However, other factors such as applicability of state standards or discharge requirements would increase costs significantly.

In order to forecast total project costs, the five site-specific evaluations and their lowest cost estimates were extrapolated to the remaining 19 UMTRA Project sites. Factors that control the costs in the sitespecific evaluations were determined and ranked. For each of the 19 
remaining sites, the cost-controlling factors were evaluated to determine the closest match to one of the five modelled sites. For this extrapolation, it was assumed that 25 percent of the costs were fixed and 75 percent varied according to the total mass of contaminants in the groundwater and soil. Because the level of technical information available for each site varies, confidence in extrapolating a restoration cost also varies. Additionally, the sites which were specifically modelled offer higher degree of precision regarding restoration, duration, and other factors.

To estimate a total program cost based on the lowest site remedial action costs described adove, the ratio of total program cost to the site remedial action costs for the current UMTRA Project was calculated. The current UMTRA Project size remeaial action cost is the cost of tailings pile remedial action at the 24 UMTRA Project sites. The total project cost includes: site remedial action cost; site characterization; planning and design development; site acquisition; technology development; pilot scale testing; economic evaluation and optimization; cost estimating; envi roumental health and safety; and technical and managerial supervision. Based on progress to date, the site remedial action cost multiplied by a factor of 2.3 yields the total project cost. Because aquifer restoration of inorganic constituents has not been accomplished at the scale required for UMIRA Project sites, the historical UMTRA Project cost factor (2.3) is a conservative estimate of the site remedial action cost and other "nonconstruction" resources needed to comply with the standards. Both the base cost and the total project cost estimates are presented in Table 4.2. Additional supporting information is available in the DOE UMTRA Project Office, Albuquerque, New Mexico.

EPA estimated costs for only 12 of the 24 UMTRA Project sites. The total cost for these 12 sites, under the EPA's most prodabie scenario, is $\$ 154$ million. The DOE estimate for aquifer restoration for these same 12 sites is $\$ 628$ million (1987 dollars).

\subsection{POST-DISPOSAL MONITORING REQUIREMENTS}

The proposed EPA standards would require a more comprehensive postdisposal monitoring program than is currently included in the UMTRA Project Surveillance and Maintenance Plan. This is because the proposed standards mandate monitoring at disposal sites (24) and former processing sites (approximately 10). The intent of this monitoring is to determine and ensure that cleanup or contamination control is functioning as designed or projected. Table 4.3 provides the comparative monitoring requirements.

The estimated additional project cost of groundwater quality monitoring for 30 years (including well installation and abandorment) is $\$ 45.82$ milition (costs in 1987 doliars). These costs are in addition to the groundwater remedial action costs described in the preceeding part of this section (see Appendix $A$ ).

\subsection{OTHER COST IMPACTS}

The proposed standards may be ARARs for other DOE programs, and possibly non-DOE sites containing large volumes of naturally occurring and 
Table 4.2 Estimated costs by site

\begin{tabular}{|c|c|c|}
\hline Site & Base & Project \\
\hline $\begin{array}{l}\text { Ambrosia Lake, New Mexico } \\
\text { Belfield, North Dakota } \\
\text { Bowman, North Dakota } \\
\text { Canonsburg, Pennsylvania } \\
\text { Durango, Colorado } \\
\text { Falls City, Texas } \\
\text { Grand Junction, Colorado } \\
\text { Green River, Utah } \\
\text { Gunnison, Colorado } \\
\text { Lakeview, Oregon } \\
\text { Lowman, Idaho } \\
\text { Maybeli, Colorado } \\
\text { Mexican Hat, Utah } \\
\text { Monument Valley, Utah } \\
\text { Narurita, Colorado } \\
\text { Rifle, Colorado (New) } \\
\text { Rifle, Colorado (0ld) } \\
\text { Riverton, Wyoming } \\
\text { Salt Lake City, Utah } \\
\text { Shiprock, New Mexico } \\
\text { Slick Rock, Colorado }\end{array}$ & $\begin{array}{r}46.98 \\
4.50 \\
7.49 \\
8.82 \\
11.15 \\
347.68 \\
6.34 \\
24.04 \\
24.02 \\
18.01 \\
7.49 \\
6.18 \\
79.89 \\
27.10 \\
4.45 \\
4.17 \\
4.10 \\
15.40 \\
4.57 \\
6.40\end{array}$ & $\begin{array}{r}108.05 \\
10.35 \\
17.22 \\
20.28 \\
25.66 \\
799.67 \\
14.59 \\
55.29 \\
55.24 \\
41.41 \\
17.22 \\
14.21 \\
183.74 \\
62.33 \\
10.23 \\
9.58 \\
9.42 \\
35.41 \\
10.52 \\
14.71\end{array}$ \\
\hline $\begin{array}{l}\text { (North Continent) } \\
\text { slick Rock, Colorado } \\
\text { (Union Carbide) } \\
\text { Spook, Wyoming } \\
\text { Tuba City, Arizona }\end{array}$ & $\begin{array}{r}4.41 \\
53.83 \\
24.57\end{array}$ & $\begin{array}{r}10.15 \\
123.81 \\
56.51\end{array}$ \\
\hline TOTALS & 745.68 & 1715.07 \\
\hline
\end{tabular}

Notes: Cost summary presents lowest cost of various options. Costs in millions of dollars (constant 1987 dollars). Base costs are estimated physical cost. Project costs are base costs $\times 2.3$ (see Section 4.2). 
Table 4.3 Comparative post-disposal groundwater monitoring requirements
Current $^{a}$
Proposed standards ${ }^{b}$

Monitoring may not be required at some disposal sites; guidance to determine need and extent provided

Monitoring for background/ baseline-quarterly for one year.

Detection monitoring-semiannual for five years and annual thereaf ter.

Soil/rock chemical analyses as needed.

Well hydraulics - 3 slug tests per well (once) and water level measurements at detection monitoring frequency.

Monitoring in the event of exceedance consisting of resampling/analysis of wells, adding wells, health risk evaluation, restoration; determined at time of occurrence.
Required at all disposal sites and former processing sites from which tailings have been relocated; guidance to determine extent provided.

Same $(192.02(a)(3)($ iv $))$.

Detection monitoring at least semiannually (264.98(d)) for "few decades" (30 years-264.117(a)(1)) or during institutional controls plus "few decades."

Not specified.

Flow rate and direction in uppermost aquifer at least annually (264.98 (c)i.

Monitoring in the event of an an exceedance (264.94) consisting of resampling/analysis of wells $(264.98$ (h)), engineering feasibility study (264.99(i)), corrective action (264. 100); additional guidance provided.

Basis is Guidance for UMTRA Project Surveillance and Maintenance, 1986, UMTRADOE/AL-360+24.0UUU.

basis is proposed standards ( 40 CFR Part 292). 
accelerator-produced radioactive materials waste. The secondary implementation costs associated with this standard due to these ARARs could be very significant and should be at least considered and recognized by the EPA. While other DOE projects have begun to evaluate the technical and budget implications or the proposed standard, no budget impact is avail. able at this time. However, it is estimated that the costs of implementing these standards as ARARs could be in the hundreds of millions of dollars. 


\subsection{ASSE SSMENT OF IMPACTS OF SUPPLEMENTAL STANDARDS}

\subsection{INTRODUCTION}

Subpart $C$ of the proposed EPA standards provides that supplemental standards may be invoked if:

- Restoration would cause more enviromental harm than it would prevent, or

- Restoration is technically impracticable from an engineering perspective, or

- The groundwater is Class III.

The implementing agencies may apply supplemental standards that ensure, at a minimum, protection of human health and the enviromient.

The DOE's assessment of these issues is aiscussed be low.

\subsection{ENVIRONMENTAL HARM}

There is no experience to draw upori to estimate environmental harm "that is long-term, manifest, and grossly disuroportionate to health benefits that may reasonably be anticipated" (40 CFR Part 192.21(b)). The preamble to the standards provides a single example where "fragile ecosystems would be impaired by any reasonable restoration process...." Given the lack of experience and general criteria to estimate environmental harm, it is clear that this issue will require careful evaluation on a site-specific basis and close consultation with the NRC as a concurring agency.

The DOE may find it useful to employ the tools of cost/benefit analysis to determine that "...harm is grossly disproportionate to... benefits..." It would be appropriate for the EPA to indicate in the record that this could be an acceptable approach. Thus, the DOE, with Fic concurrence, would carefully and extensively evaluate the possible and likely enviromental harm from various aquifer restoration scenarios, estimate the health benefits from these restoration scenarios, and then evaluate whether the costs are clearly, unreasonably high realtive to these benefits. This approach would ensure protection of human health and the envirorment and yet apply priority waste cleanup funds at sites having clear impacts to human health and the envirorment.

\subsection{TECHNICAL IMPRACTICABILITY}

The proposed EPA standards preamble notes: "the word practicable is not identical in meaning to the word practical. As used here, the former means able to be put into practice and the latter means cost-effective." 
The concept of "cost-effective" has long been used, and there is general agreement about its meaning. The same is mot true of the concept of "technically impracticable" or "not able to be put into practice."

For example, it may be technically impracticable to perform an action because the technology does not exist, although in theory such technology could be developed. It may be technically impracticaole to perform an action because there is not a method available to achieve the ends sought within the bounds of financial resources or the time-scales over which such work can be controlled. A remedial action may be technically impracticable because there are established mutually exclusive technical criteria (i.e., it simply is not possible to comply with multiple rules at once).

While the above examples of technical impracticability can be envisaged, it is also conceivable that many others exist. (For example, see Section 3.7.) The topic is one that has not been explored elther philosophically or technically by agencies. There is no common experience or consensus on the criteria for judging or establishing technical impracticability. Accordingly, the DOE believes that the matter should be left to the DOE and the NRC to deal with cases of technical impracticability on a site-specific basis. Additional discussion can be found in Section 6.4.1.

\subsection{CLASS III GROUNDWATER}

The criteria for assigning groundwater as Class I, II, or III are presented in the EPA's proposed guidelines for implementing their groundwater protection strategy (EPA, 1986). In those guidelines, Class III groundwater is defined as groundwater that (1) contains more than $10,000 \mathrm{mg} / 1$ TDS; (2) is contaminated naturally or from human activities to the extent that it cannot be cleaned up using treatment methods reasonably employed in public water-supply systems; or (3) is in aquifers that yield less than 250 gallons per day to wells.

The proposed standard of $10,000 \mathrm{mg} / 1$ TOS is more conservative than is necessary to set the upper concentration for human consumption. Therefore, the DOE proposes that lesser concentrations of TDS be evaluated as possible limits for the designation of Class III groundwaters at UMTRA Project sites. As an alternative, however, a process could be specified that would demonstrate that human health and the environment could be protected given the extent of restoration and, thus, the intent of class III water designation would be met. Additional discussions are contained in Section 6.4.4. 


\subsection{RECOMMENDATIONS}

Previous sections of this report estimate the work that may be required to implement the proposed EPA standards. This report has also noted that at most disposal sites, compliance with the proposed EPA standards may not be possible without application of ACLs or supplemental standards.

This section summarizes the aspects of the proposed standards that DOE believes require modification, and proposes reasonable interpretations of aspects that currently are open to interpretation. The addition of reasonable interpretations along with modifications to the proposed standards will enable the DOE and the MRC to reach groundwater remedial action agreements expeditiously while ensuring protection of human health and the enviroment.

\subsection{RISK ANALYSIS}

A principal issue of concern to the DOE is the lack of a health and enviromental benefits analysis as a technical basis to support the proposed standards. In 1983, the EPA performed a risk analysis as part of its standards setting process. As noted by the National Research Council (1986), this risk analysis was deficient because "(1) it adopts specific model formulations without adequately comparing their appropriateness with possible alternative model forms and then uses single-value estimates in those models rather than a range or full probability distribution, (2) it provides little discussion of the uncertainties and sensitivities of the resultirig assessments of health impacts, and (3) it focuses primarily on radioactive exposures ano pays insufficient attention to assessing risks from contaminated groundwater."

These deficiencies remain.

The DOE recognizes that the UMTRCA requires that the promulgation of standards "shall, to the maximum extent practicable, be consistent with the requirements of the Solid Waste Disposal Act, as amended." The DOE supports the basic intent of the proposed standards to protect human health and the enviroment. However, the lack of a satisfactory risk assessment poses interpretation problems in those areas where the implementers have the responsibility under the standards to judge the reasonableness of certain actions. We believe that the implementers' task would be facilitated by an EPA description of the benefits of this major groundwater protection policy.

\subsection{ALTERNATE CONCENTRATION LIMITS (4U CFR Parts 192.02(a)(3)(v) and} $192.12(C)(2))$

The ACL guidance established by the EPA for RCRA permitting relates primarily to the active life of the site and for an "active" post-closure period. UMTRA Project sites differ from most hazardous waste sites in that the techniques and methods used in remediation result in a lesser need for maintenance and an assured longevity of 1000 years. Therefore, the DOE believes that the EPA should establish generic criteria and 
specific guidance for the establishment of $A C L S$ at UMTRA Project sites, consistent with current RCRA ACL guidance (EPA, 1987a) with the following modifications:

- Institutional controls, coupled with the concept of the Point of Human Exposure for Class II waters should be permitted, rather than the Point of "Environmental" Exposure, as is currentiy used. The EPA has recognized the need and value of insticutional controls (e.g., government ownership of land) in aid of long-term control of stabilized uranium tallings plles. The DOE recognizes that the use of institutional controis are not intended to subvert the intent of the standards and this recognition, coupled with the NRC's concurrence role, will ensure that these controls are applied as the exception rather than the norm.

- ACLs should explicitly apply for perfods beyond the remedial action and post-closure periods.

- Existing contaminant plumes should be permitted to increase in size during periods of passive restoration when human health and the environment are protected. This may allow dispersion, dilution, and attenuation to meet MCLs or background, as appropriate.

The purpose of these suggested modifications is to clarify the intent and basis for setting and implementing ACLs. In any event, the final standards should emphasize the primary need to demonstrate protection of human health and the environment.

\subsection{POINT OF COMPLIANCE (POC)}

The proposed standard incorporates the RCRA definition (40 CFR 264.95 ) of the POC for Title I disposal sites. The DOE belleves that techIlical clarification of how the RCRA regulation should be applied to UMTRA Project sites is necessary so that RCRA intent can be reconciled with UMTRA Project longevity objectives. If specific design differences between RCRA and UMTRA Project facilities are not recognized in locating the UMIRA Project POC, the proposed standard will not be ach fevable at aimost all UMTRA Project disposal sites.

If the RCRA POC definition summarized in section 2.0 of this report is applied as it is stipulated for RCRA-permitted facilities, the present UMTRA Project design basis stressing longevity and passive long-term control will be in conflict with the proposed standards.

The UMTRA Project design approach relies on natural materials to provide a reliable system of control for at least several centuries. Unilike RCRA containment systems, wich are engineered to provide 100 percent hydraulic isolation using multiple layer synthetic barriers and active leachate management systems, UMTRA Project designs are best described as controlied relo?se systems. As such, UMTRA Project sites allow some percolation through ie tailings, but do not release constituents to the environment above ssign objectives that ensure protection of human health and the environment (see Section 3.0). 
In order to accomplish this passive control for the specified design requirement, UMTRA Project designs rely on the underlying geology (and/or geochemical barriers) to perform an attenuation/dispersion function throughout facility life. The subsurface geology is fully characterized so that long-term, steady-state system performance can be predicted. Essentially, the site geology functions as an integral component in the UMTRA Project design system. The actual downgradient distance required to attenuate constituents to the proposed MCLs is highly dependent on site and facility design attributes, but is predicted to extend 100 to 1500 feet from the downgradient edge of the pile.

The POC specified for UMTRA Project sites must reflect this reliance on underlying geology (and/or geochemical barriers as appropriate) as a component of the "waste management area." While different than for a RCRA facility, UMTRA Project facilities cannot reliably meet the proposed constituent concentration limits at the downgradient edge of the disposal pile as direct consequence of the UMTRA Project design approach.

The concept of a mixing zone/buffer zone around the disposal pile is also part of the long-term institutional control plan for UMTRA Project sites, as is the long-term need for surveillance, maintenance, ano monitoring after remedial actions are complete. Such zones are included in other envirormental regulations (e.g., surface water effluent limitations), and the DOE assumes them to be consistent with EPA intent under appropriate circumstances.

Thus, the DOE concludes that implementing the proposed standard will be enhanced by explicitly defining the UMTRA Project waste management area to include the underlying geology which contributes to the overall facility performance. This could be accomplished by redefining the RCRA POC (for UMTRA Project sites, with MRC concurrence) or by stipulating that the POC must not exceed a reasonable, specified distance downgradient of the pile. Without such clarifications, the longevity requirements of Subpart A (40 CFR $192.02(a)(1))$ and the minimum closure maintenance objective of Subpart A (40 CFR $192.02(a)(4))$ could be in conflict with the RCRA POC provision ( 40 CFR $192.02(3)$ ).

\subsection{SUPPLEMENTAL STANDARDS (40 CFR Part 192.20 through 192.22)}

\subsubsection{Technical impracticability}

Previous sections of this report discuss the philosophical basis of technical impracticability (Section 5.3) and present examples applicable to disposal site remedial action design (Section 3.7). Question 14 of Section 7.0 also addresses the criteria that should be considered for judging technical impracticability.

The concept of technical impracticatility is a recent development which has not yet been conclusively applied in remediation. The DOE believes that there are numerous examples of technical impracticability that could preclude compliance with Subparts $A$ and $B$ of the proposed standards and would invoke the use of supplemental standards. 
The DOE recommends that the application of the concept of technical impracticablitity be left unembellished in the standards and that interpretation be left to the judgement of the NRC and the DOE. The onus would be on the DOE to identify cases of technical impracticability and to argue for the application of this concept in specific cases on the UMTRA Project (and other affected DOE projects).

In the event that the EPA elects to specify criteria in the final standards for technical impracticability, the DOE requests an opportunity to review the criteria prior to their promulgation and would recommend that the following be included at a minimum:

- Absence of technology to achieve the desired goals (1.e., MCLs).

- No methods available to achieve these goals within the bounds of financial resources or the schedules over which such work can be controlled.

- Two or more mutually exclusive technical criteria, rules, or laws.

The DOE recognizes that a finding of technical impracticability should not simply be used to justify a course of no action. If technical impracticability is found to exist, the DOE believes that an evaluation should be undertaken as a practical attempt to apply controls or conduct partial cleanup in an attempt to meet the standards with consideration of the costs incurred for the benefits achieved. This concept is further discussed in Section 6:4.3.

\subsubsection{Supplemental standards exciusion}

Part 192.22 (d) of the proposed standards requires that the implementing agencies must, at a minimum, protect human health and the enviroment when invoking supplemental standards. This is reasonable.

As written at present, however, the standards state that "implementing agencies must apply any remedial actions for the restoration of contaminated groundwater that is required to assure, at a minimum, protection of human health and the environment." This woraing could be construed to mandate groundwater restoration at all sites, even when conditions of technical impracticability or Class III groundwater exist.

The DOE believes that this statement should be clearly understood to address the protection of human health and the en'ironment, and not constitute mechanism for requiring inappropriate or technically unne essary actions. 


\subsubsection{Consideration of costs and benefits}

The proposed standards state that costs are not to be considered in the decision to restore contaminated groundwater (i.e., practical vs. practicable). On the other hand, however, the supplemental standards (Part 192.22(a)), in referencing the concept of technically impracticable (Part 192.21(f)), states that ". . agencies shall. ..pertorm remedial actions that come as close to meeting the otherwise applicable standard as is reasonable under the circumstances." This latter statement could be incerpreted as a practical attempt to apply the controls to meet the standards with consideration of the costs incurred for the benefits achieved. This possible contradiction will pose interpretation difficulties for the implementing agencies and the DOE requests clarification on the final standards.

The DOE is sensitive to the substantial national consensus that groundwater protection and restoration provide worthwhile environmental and resource benefits. The DOE also recognizes that supplemental standards are not intended to subvert the general judgements that are implicit in the standards. However, the EPA elsewhere in these standards provided a means to reasonably address exceptional circumstances in which the costs or environmental harm of remediating lands and buildings would be clearly excessive relative to the long-term benefits (see Part $192.21(b)(c)(d))$. In such circumstances, the implementers may use the supplemental standard (Part 192.22(a)) identified above. The DOE believes that the implementers require similar flexibility on interpreting and responding to situations where remedial actions for groundwater may be technically impracticable. The DOE requests, therefore, that the concept of unreasonably high costs in relation to benefits be explicity stated as relevant to deciding that supplemental standards are warranted because of technical impracticability.

The DOE recognizes (see Section 5.3) that the concept of impracticable means "not able to be put into practice" as opposed to cost effective. However, Congress in SARA recognized that costs may be an important consideration when "... a remedial action...will not provide a balance between the need for protection of public health and welfare and the environment... and the avaliability of amounts from the fund to respond to other sites wich present or may present a threat to public health or weifare or the environment..." (Section $12 i(d)(4)(F)$ ). The DOE is also sensitive to the demand for waste remediation funds and believes that such funds should be expended on remediation at sites having clear, current or future human health and environmental hazards. Thus, the DOE requests that costs and benefits consideration be included in the final standards.

\subsubsection{Class III waters}

The DOE assigns great importance to the possible use of supplemental standards at sites where groundwater falls in EPA's pro- 
posed Class III. However, the DOE believes that the criterion of $10,000 \mathrm{mg} / 1$ for TOS is more conservative than necessary in setting the upper concentration for human consumption and asks that the EPA evaluate a lower TDS threshold. Furthermore, the DOE recognizes that the EPA groundwater classification system is not final, and thus the criteria for class III could change as a result of an EPA rulemaking separate from the promulgation of the Title I groundwater standards. Therefore, the DOE requests that in these groundwater standards a special Class III groundwater be explicitly defined for the UMTRA Project. The criteria for this category would be:

- A TOS threshold concentration lower than the present i0,000 $\mathrm{mg} / 1$, or

- Widespread ambier.' contamination that cannot be cleaned up using methods reasonably employed in public water treatment, or

- Well yields of less than 150 gallons per day.

As an alternative to the inclusion of special Class III designation, the EPA could specify a process by which it would be demonstrated that human health and the environment would be protecred by the considered restoration. Class III groundwaters are not potential source of drinking water and are of limited beneficial use. Thus, the intent of this designation is to protect human health and the enviroment through the avoidance of resource use.

At several UMTRA Project sites, groundwater is marginally Class II. For example, at the Salt Lake City processing site, the currently contaminated alluvial aquifer is a lower quality class 11 (approximately 800 to $1600 \mathrm{mg} / 1$ TOS). The site has limited irrigation use downgradient (small homeowner gardens) and a highly used and abundant alternate drinking water source (i.e.. metropolitz.n Sal. Lake uses a deeper, higher quality (lass II groundwater). There is little, if any, interconnection between the two aquifers because of the lower unit's upward hyoraulic gradient. Thus, in this case, the intent of the Class III supplemental standard would be met regardless of the extent of aquifer restoration.

The DOE believes that this type of analysis could be performed for UMIRA Project sites that overlie Class II waters. Should the DOE's analysis demonstrate to the NRC's satisfaction that complete restoration is unnecessary to protect long-term human health and the enviroment, then partial or no restoration would occur. Therefore, the DOE requests tiat the EPA consider this alternative.

\subsection{POST-DISPOSAL MONITORING}

The proposed standards, 4U CFR Part $192.02(\mathrm{~b})$, require that the DOE implement a post-disposai monituritig progiam to verify the performance of 
the disposal site. Although the extent of such monitoring is to be determined by the DOE with NRC concurrence, the DOE believes that monitoring may not be required at certain sites. For example, monitoring may not be necessary at sites that are separated from the uppermost aquifer by thick sequences of low-permeability and/or highly attenuating materials. Thus, the DOE believes that in the final standards the EPA should maintain the performance monitoring fiexibility of the proposed stanoards and indicate that monitoring may not be needed under certain conditions.

\subsection{CORRECTIVE ACTION}

40 CFR Part 192.0\%(C) requires "a corrective action program to restore the disposal (SIC) to the design requirements of 192.02(a) and, as necessary, to clean up groundwater in conformance with Subpart B. . . " The DOE believes that such mandatory action may not be necessary at every site to ensure protection of human health and the environment. For example, at a site where post-disposal performance monitoring indicates an exceedance of an MCL, an ACL that is protective of human health and the enviroment may be a cost-effective solution. Therefore, the DOE requests that Part 192.02 (c) be modified to include, in addition to a corrective action, other responses such as the setting of ACLs and the implementation of supplemental standards.

\subsection{VICINITY PROPERTIES}

The applicability of the provisions of Subparts $A$ and $B$ is not completely clear from the text and preamble. Subparts $A$ and $B$ appear to apply at any location where the DOE disposes of or removes residual radioactivi aterial, including vicinity properties. Thus, the proposed standaras uld require an extensive expansion of the UMTRA Project by requir ing 9 -undwater characterization, potential cleanup, and monitoring at more than 6000 vicinity properties that have been identified to date.

The DOE believes that it is not the intent of the EPA to require such mandatory characterization at all vicinity properties. Rather, it would appear that the EPA should allow selective judgement by the DOE and the NRC to determine when groundwater may be affected by vicinity properties. Therefore, the DOE requests such clarification in the final standards.

\subsection{COMPLETED SITES}

The preamble to the proposed standards states that the need for restoration of groundwater, and possible redesign and collstruction, at completed sites must be evaluated by the DOE. The NRC must concur with the DOE findings.

The preamble also states that "any such cleanup work should not adversely affect the control systems...already... installed." On the basis of analyses performed in support of this report (Sections 3.0 and 4.0 ), the DOE believes that additional design and control work would need to be 
performed to comply with the proposed standards at completed sites unless ACLs or supplemental standards are acceptable. Although costs have not been estimated, these activities would clearly increase the cost estimates of Section 4.0 .

Therefore, the DOE believes that the EPA should consider the inclusion of a "grandfather clause" in the final standards. It is important to note that groundwater protection was carefully considered in selecting remedial actions at each site and that the $\mathrm{MRC}$, states/tribes, and generally the EPA regional offices participated in the decisions. In addition, there is ample precedent for such clauses. For example, in Section 121(f) of SARA, compliance with new requirements is not required where remedies had previousiy been selected at the time of enactment of SARA. Such a clause would exempt from future design and construction changes all completed or substantially completed sites that perform as designed.

\subsection{OTHER DOE REMEDIAL PROGRAMS}

In addition to the UMTRA Project, the DOE manages a number of sites that contain low-level radioactive waste as part of its Formerly utilized Sites Remedial Action Program (FUSRAP) and Surplus Facilities Mariagement Program (SFMP). Insofar as there may be some broad interpretations regarding applicability of the proposed rule for groundwater standards at UMTRA Project sites, the DOE requests the inclusion of the ARAR waiver conditions identitied in SARA. The following content of SARA Section $121(d)(4)$ should be incorporated in the regulations:

The selected remedial action need not attain the levels or standards of control herein required should one of the following three conditions apply:

- The action is only part of a total remedial action that will attain such levels or standards of control when completed.

- Compliance with such requirement will result in greater risk to human health and the environment than alternative options.

- The action will attain an equivalent standard of performance through use of another method or approach. 


\subsection{RESPONSES TO EPA QUESTIONS}

In addition to soliciting comments on the entire proposed rule, the EPA requested comments and recommendations on 15 particular issues or questions. The EPA questions and the DOE responses are below.

In some instances the response to a question involves issues discussed in detail elsewhere in this report. In such cases, the reader is directed to the other parts of the report where additional information is found.

\section{Question 1}

Should a liner requirement always be imposed on tailings piles that are moved to a new location? Should a liner be required only if the DOE or the MRC conclude that it is needed to satisfy the groundwater standards for disposal?

\section{DOE Response}

Liners should not be uniformly required for relocated tailings piles. The low-permeability covers placed on UMTRA Project taiiings piles inhitit infiltration and ar'e the primary seepage control mechanism. Controlling seepage with a well-designed cover is preferable to controlling seepage at the base of the pile, as this will preclude the "bathtub" effect and eliminate or minimize lateral seepage.

Where necessary, the DOE, with MRC concurrence, will consider the use of a liner or a geochemical barrier at the base of the pile in addition to a low-permeability cover as a possible way to satisfy groundwater standards.

Additional discussion of the role and need for liners is provided in Section 4.0 .

\section{Question 2}

For designated processing sites from wich tailings have been remov ed, is a specific requirement that DOE cleanup the groundwater before releasing the land to the state or private owners needed to assure that such cleanup will occur?

\section{DOE Response}

No, a specific requirement that the DOE cleanup the groundwater before releasing the land to the state or private owner is not necessary to compel compliance with Subpart $B$. The DOE is required by Section 108 of UMTRCA (PL95-604) to comply with standards promulgated by the EPA. In addition, the DOE has cooperative agreements established pursuant to Section $1 \cup 3$ of the UMTRCA with the affected states/tribes and the MRC that 
require DOE compliance with the standards via state/tribe and NRC concurrence in the remedial action plan. Also, the issue of land acquisition and release is fully addressed in Section 104 of UMTRCA, which has been incorporated into each cooperative agreement.

Furthermore, preventing release of land to the state or private owner may lead to unnecessary restrictions on use of the land. Restoration could proceed at a site without impeding beneficial uses of the land as long as use of the groundwater is restricted by imposition of appropriate institutional controls. To require the restriction on the beneficial uses of such land for the potentially long period of aquifer restoration, or for the 100 years of potential natural flushing, is not considered necessary.

Therefore, the DOE should be permitted to release surface use of property with the concurrence of the NRC, providing that the DOE demonstrates that a significant adverse relationship does not exist between surface uses arid groundwater restoration.

\section{Question 3}

Should institutional controls be relied upon, for a limited time, to prevent access of the public to groundwater in order to permit use of natural flushing of contaminants, as proposed? If so, what types of institutional controls should be allowed? Should these de specified in the rule? Is the proposed time period appropriate?

\section{DOE Response}

This question represents four interrelated concerns; each is addres. sed separately in the following paragraphs.

i) The DOE supports the use of institutional controls as a means of preventing access of the public to contaminated groundwater. These controls should oniy be used for limited time in order to permit use of natural flushing of contaminants, as proposea.

ii) In response to the second question pertaining to whicn institutional controls should be allowed, the $D O E$ believes that the list of controls should encompass the full range of appropriate options and legal restrictions applicable to the site-specific situation. Examples of appropriate institutional controls include, but should not be limited to: (1) legal restrictions enforceable by government agencies: (2) ownership of land by government agencies; (3) appropriation of water resources during the period of natural flushing; (4) deed restrictions; and (5) provisions for alternate water supplies. Therefore, the DOE specifically requests that no limit be placed on the types of institutional controls which may be employed. 
iii) No, the DOE does not believe that a list of institutional controls should be entered into the rule. To do so would remove the flexibility which may be needed to determine the appropriate controls for site-specific conditions. While examples of acceptable institutional controis should be included in the standards, latitude should be provided so that the DOE, with MRC concurrence, is able to use the types of institutional controis that best protect human health and the enviroment at a specific site. This also would provide flexibility to use other "acceptable" institutional controls as they evolve.

iv) Yes, the DOE believes that the proposed time period of 100 years is appropriate. The choice of a 100-year duration is primarily based on confidence in maintaining institutional controls. Species-specific migration rates in various settings range widely. Movile species could be flushed in a few years, while some immodile species may take thousands of years. Because of these wide variations in migration rates, the limitation on natural flushing duration should only be based on confidence in maintaining institutional controls.

The length of time for institutional controls such as these has been explored by Federal agencies and the public since at least 1978. In 1978, the EPA proposed a 100-year limit on institutional controls based upon public input received at several public meetings. In 1981 and 1982 the NRC, in its enviromental impact statement on the licensing requirements for land disposa) of radioactive waste, examined the length of such controls in several regional workshops and through the public comment process. The RRC found that "it seems reasonable to expect that institutional controls may be reasonably effective indefinitely... MRC believes, however, the institutional controls will last at least 50 years. Three-hundred years appeared to be too long of a time period and did not offer any compelling numerical advantage over 150 years. The preferred alternative was, therefore, in the range of 100 to 150 years... Based on the comments received.... and the workshops held, the general consensus was that 100 years was about the right time period...." Since then, the EPA has established similar concepts for institutional controls in their regulations for managing and disposing of high level wastes (40 CFR Part 191).

\section{Question 4}

Should the option to make use of matural flushing for cleansing of contaminants be limited to cases where some restoration of the grounawater has already been carried out? Should the use of an ACL be permitted, as proposed, in the case of cleanup to be achieved (in whole or part) by natural flushing? 


\section{DOE Response}

No, natural flushing should be allowed in conjunction with active restoration or as a sole mechanism for cleanup of contaminants if the concentrations of those contaminants will decline to the appropriate concentration limit within the period of institutional controls. If sone active restoration is required prior to natural flushing and institutional controls, the extent and objectives of partial restoration will be extremely difficult to establish. If in the final rule the EPA elects to require some restoration prior to natural flushing, the DOE requests at the EPA develop specific guidance regarding the objectives of such limited restoration and an opportunity to review such guidance prior to its promulgation.

Yes, ACLs should be permitted where groundwater restoration would involve natural flushing. As stated in the EPA's guidance for Alternate Concentration Limits (EPA, 1987a), "To obtain an ACL, a permit applicant must demonstrate that the hazardous constituents detected in the groundwater will not pose a substantial present or potential hazard to human health or the environmert at the ACL levels." Given that ACLs will protect human heaith and the environment in the specific hydrogeologic circumstances, and considering the expected pattern of groundwater use and other factors, it is reasonable that ACLs should be permitted for all cases of cleanup.

\section{Question 5}

Are the proposed bases for supplemental standards for cleanup reasonable and adequate for the protection of human health? Should other bases be provided and, if so, what are they? Should the provisions for natural flushing and supplemental standards for cleanup apply only to existing contamination or should they also apply, as is proposed, to "new" contamination due to failure of the disposal design to perform as intended?

\section{DOE Response}

The response to this question should be read in conjunction with the more detalled discussions in Section 6.0 of this report.

The DOE believes that the proposed bases for supplemental standards (40 CFR Part $192.21(b)(f)(g)$ ) are reasonable for the protection of human health and the environment. However, the DOE requests that the bases for the use of supplemental standards be extended by:

- Modification of 40 CFR Part 192.22(a) to specifically include the consideration of costs and benefits, and

- Rewording 40 CFR Part 192.22(d) to clarify that groundwater restoration is not necessarily recuuired when supplemental standards are invoked.

The DOE believes that supplemental standards and natural flushing should also apply to "new" contamination due to failure of the disposal 
design to perform as intended. This approach is justified because supplemental standards can be applied only when the groundwater has an extremely low potential for extraction and use and when sufficient remedial action is undertaken to protect human health and the environment.

\section{Question 6}

Under these proposed standards, ACLs would be concurred in by the KRC. Should the EPA establish generic criteria and/or guidance governing the application of the provisions of 40 CFR Part 264.94 (b) of this Part to these judgements for these standards?

\section{DOE Response}

The DOE believes that the EPA should establish generic criteria and guidance for the establishment of ACLs as per the current RCRA ACL guidance (EPA, 1987a) as modified for Title II sites. Also, as noted in detail in Section 6.0 of this report, the DOE requests that the EPA provide additional flexibility to the RCRA ACL guidance, specifically regarding the point of exposure, the period of applicability of $A C L S$, release of contaminants to surface waters, and other provisions.

\section{Question 7}

Should the EPA publish, as part of this standard, a restricted list of just those radioactive and toxic constituents that are present at these sites, or continue to rely on the entire list (supplemented as proposed) of constituents encompassed by RCRA regulations? Should the proposed list of additional listed constituents be changed?

\section{DOE Response}

No, the DOE believes that a restricted list of constituents is not warranted. The DOE's general approach to characterizing groundwater contaminacion is to apply a screening level, multiphased program for all suspected contaminants. The screening program is followed by a decailed determination of those contaminants that were detected in the screening program. The DOE Delieves that this approach is appropriate and should be continued. The proposed list of additional listed constituents should not be changed. Based on existing data, the added constituents (uranium, molybdenum, and nitrate) are regularly present in the groundwater beneath and downgradient of UMTRA Project sites as a result of tailings leachate.

\section{Question 8}

The EPA could consider publishing a restricted list of just those radioactive and toxic constituents that are principal contaminants at these sites and specifying a limit for each of these, under the assumption that any minor contaminants would be taken care of in the cleanup of these principal contaminants. With such a restricted set of constituents and 
corresponding complete set of 11 mits, the EPA could then consider dropping the provistons for ACLs and relying solely on the remaining provisions for exceptional cases. Should the EPA adopt this approach?

\section{DOE Response}

No. As stated in the response to Question 7, the DOE belleves that a restricted list of constituents is not warranted.

Provisions for ACLs (and the guidance discussed in Section 6.0) mus c, however, remain to allow flexibility for the judicious use of $A C L s$ wh'le at the same time demonstrating that human health and the enviromeilt wol'ld not be adversely affected.

\section{Question 9}

Should the EPA specify a minimum or the entire period for post-disposal groundwater monitoring in Subpart $A$, or leave it to the DOE and NRC to determine this period on a site-specific basis, as proposed? If the EPA should specify a period, what length would be appropriate to demonstrate conformance to the disposal design standard, and on what basis should this value be chosen?

\section{DOE Response}

The period for post-disposal groundwater monttoring should be determined by the DOE with concurrence by the MRC on a site-specific basis. Factors given in 40 CFR Part 264.117 wauld be considered in establishing the site-specific monitoring period. The approach of "DOE proposes and NRC collcur s" has worked well in the establishment of survelllance and maintenance which includes post-closure groundwater monitoring requirements. A memorandum of understanding addresses the basic requirements applicable to Title I sites and the site surveillance and maintenance pians address specific site requirements.

In addition, the DOE believes that monitoring may not be required at certain disposal sites. For example, groundwater monitoring may not be required for sites that are separated from the uppermost aquifer by thick sequences of shale or other types of low-permeability and/or highly attenuating materials, sites that are above Class III waters, or sites where the water table is deep. Further, mandatory performance monitoring is based upon RCRA facilities using technologies and methods that may result in a relatively short design life, whereas the specified design life of Subpart $A$ is 1000 years. Thus, the DOE requests that the EPA reconsider 40 CFR Part 192.02 (b) and delete its requirements for mandatory mont toring.

Notwithstanding the DOE position for UMTRA Project sites, should the proposed standards be ARARs at other DOE sites (e.g., FUSRAP/SFMP), the definitions of "remedial period" and "post-disposal period" would need to be revised to retlect the unique concerns of those sites. Unlike the UMTRA Project sites, mariy FUSRAP/SFMP sites involve interim storage of contaminated materials pending the selection of a permanent disposal site. 
In some cases, potential sites have not yet been identified as candidates for permanent disposal. Thus, interim storage could continue for several years. Accordingly, the DOE requests that the EPA i larify that the definttions of remedial action period and post disposal period as proposed are unique to the UMTRA Project.

\section{Question 10}

For tailings regulated by the NRC under Title II of the Act, Section $84(a)(3)$ requires the MRC to develop regulations to conform to general requirements applicable to the possession, transfer, and disposal of hazardous materials regulated by the Adninistrator. Should the standards proposed here incorporate such requirements for tailings regulated under Title I?

\section{DOE Response}

No, such additional requirements are not necessary. Under Title I, the DOE, with KRC oversight, has accepted environmental protection responsidilities and developed proceaures for the possession, transfer, and disposai of tallings and other contaminated materials. Regarding wastes not containinated by the milling process, the DOE and its contractors are bound by applicable Federal and state regulations for the possession, transfer, and disposal of these wastes. At the Title I Canonsburg. PA, and Ambrosta Lake, $M$, sites, for example, the DOE and its contractors worked successfully with the applicable state agencies to ensure that the transfer and disposal of these wastes were in full compliance with the regulations. Therefore, the currently applied Titie I process would not be facilitated or improved by the imposition of additional regulations tallored to control permittee possession, transfer, and disposal of hazardous materials. The DOE is not in favor of incorporation of Title II solid waste hazardous materials regulations into the standards.

\section{Question 11}

Is it appropriate to base the uranium contaminant limit on radioactivity alone or should the chemical toxicity of uranium resuit in a more restrictive value?

\section{DOE Response}

Chemical toxicity should be considered in establishing a regulatory limit for uranium, but available human or animal data to accomplish such an evaluation may be too limited to definitively answer this question.

The limited data suggest that for animal species, the no-ooservableeffect level (NOSL) ranges from 0.1 to $1.0 \mathrm{mg} / \mathrm{kg} /$ day. Based on these che motoxicity data, the EPA has calculated an adjusted acceptable daily intake (AADI) of 6 to $60 \mathrm{ug} / 1$ (EPA, 1985). The AADI incorporates a safety factor of 100 for interspecies varlation and assumes that drinking contributes 90 percent of dally uranium ingestion. The AADI corresponds to a range of radioactivity level of four to $40 \mathrm{pCi} / 1$. 
A MCL of $30 \mathrm{pCl} / 1$, based on predicted carcinogenic risk due to radiotoxicity, has been proposed. This value is within the upper part of the AAOI range developed by the EPA based on chemotoxicity data. It is important to note that, unlike carcinogenic risk, the risk of noncarcinogenic effect occurring is not assumed to be proportional to the dosage. This is due to the assumption that carcinogenic is a no-threshold phenomenon, while there is a threshold ror noncarcinogenic effects. Therefore, al though the AADI range varies by an order of magnitude, the 10-fold ditference in dosages in the range implies that the risk (or severity) of noncarcinogentc effects would be 10 times greater if the standard were set at $60 \mathrm{ug} / 1$ as opposed to $6 \mathrm{ug} / 1$. It is theoretically possible, for example, that the threshold for adverse effects lies somewhere within that range.

The lowest no-effect level for chemotoxic effects in animals is uncertain at this time. If it is assumed that the more conservative value is valia, then the drinking water standard based on this value $(6 \mathrm{ug} / 1$ or 4 $\mathrm{pCi} / 1$ ) would be 7.5 times lower than that proposed by the EPA (30 $\mathrm{PCi} / 1)$ based on radiotoxicity. However, the proposed standard is still $10 \mathrm{pCl} / 1$ be low the upper NOEL. which incorporates a safety factor of 100 . Therefore, given the uncertainty in the avallable data, the EPA may lyish to consider chemotoxicity of uranium in the final standards.

\section{Question 12}

Should the Agency consider revising the Title II regulations to incorporate these portions of the Title I regulations that are different from the Title II regulations; e.g., the additional contaminant limits in Table A?

\section{DOE Response}

No, the DOE does not believe that the regulations must be made consistent. However, the DOE is concerned with this issue only to the extent that it may affect agreements and remedial actions in effect with states and the NRC (e.g.o relocation of the Title I Riverton tailings to a Title II site). In this case, Title I standards would be applied to the clearlup of the Title I Riverton mill site. The Riverton tallings would ve commingled with the tallings extant at a Title II disposal site; final reclamation would be performed in accordance with reclamation plan approved by the NRC under Title II requirements of the NRC and EPA. The enviromental and health hazards at the Riverton mill would be addressed and the tallings disposed of in a manner that would address the long-term control requirements of the Act.

At the Tennessee Valley Authority (TVA) Title II disposal site in Edgemont, South Daxota, the DOE is transporting Title I vicinity property materials for commingled disposal with Title Il tallings. The disposal is performed pursuant to a license amendment issued by the NRC and in accordance with an agreement between the DOE and the TVA which was concurred in by the state and the NRC. Thus, the DOE proposes that revisions to Title II regulations be made only to the extent thot current agreements and approaches as described above remain unaffected. 
Are the estimated costs of implementing these proposed standards accurate and based on reasonable assumptions?

DOE Response

No. The cost estimates in the Background Information Document (BID) (EPA, 1987b) are based on overly simple assumptions and on limited data. These assumptions include the following:

- Estimateo extent of groundwater contamination.

- Estimated range of unit costs to extract and treat groundwater.

- Estimation that 1 to $\$ 5$ volumes (average of 5 volumes) would need to be removed to accomplish restoration to EPA standards.

In addition and as acknowledged in the BID, many items are not included in the cost estimates such as monitoring equipment, data collection activities, discharge or reinjection facilities and operations, removal and remediation of factlities, final revegetation, and well abandonment. Other items not acknowledged in the BID that would contribute to more accurate estimates inciude additional site characterization, regulatory and permitting procedures, and design and contractor overhead.

Also, the BID only considered information from 12 of the 24 sites. One site not considered, Falls City, has an inordinately high restoration cost because of its $p$ lume size and contaminant concentrations. Additional details are available in Section 4.0 and Appendix $A$.

In adaition to the above discussions, the proposed standards may be ARARS for other DOE remedial action programs. No consideration has been given in the BID to the costs of implementing these standards outside of the UMTRA Project. While detalled estimates for these other remedial action projects are not yet available, incremental costs of hundreds of millions of dollars are probable.

Question 14

What criteria should be used to judge "technically impracticable from an engineering perspective"? Can and should these criteria be specified in thi: rule, or should they be left to the judgement of the DOE and the RRC?

DOE Response

The concept of technical impracticability is a recent development and has not yet been conclusively applied in remediation. The application of this concept shoula be left to the judgement of the DOE and the NRC. 
Should EPA elect to specify criteria in the final standards, the DOE requests an opportunity to review the criteria prior to their promulgation. As discussed further in Section 6.0, the DOE believes that if the supplemental standard of technical impracticablitity is applied on a caseby-case basis, the DOE would develop extensive documentation, including an evaluation of the degree to which remediation is possible, and then consider the costs and benefits.

\section{Question 15}

The criteria proposed here to specify groundwater as Class III, and therefore qualified for supplemental standards, are based on draft proposals still under consideration by the Agency. Are these criterta appropriate for this application, or would others be more appropriate for use at these sites?

\section{DOE Response}

The DOE requests that a special class of groundwater be defined specifically for the UMTRA Project. The new class would replace Class III groundwater as used in the currently proposed EPA groundwater classitication scheme. Criteria for including groundwater in the new class would be :

- Widespread ambient contamination that cannot be cleaned up using treatment methods reasonably employed in public water supply systems, or

- Well yields or less than 150 gallons per day, or

- A total dissolved solids threshold concentration limit that is lower than the present $10,000 \mathrm{mg} / 1$. (Evaluation of an appropriate total dissolved solids limit would have to be undertaken by the EPA in order to establish an acceptable limit.)

As an alternative, however, to the inclusion of a special class III designation, the EPA could specify a process by which human health and the environment would be protected and aquifer restoration may be minimized.. Class III groundwaters are not a potential source of drinking water and are of limited use. It is clear that EPA's intent in including Class III groundwater in supplemental standards is to avoid or minimize restoration wile protecting human health and the environment through avoidance of resource use.

The DOE believes that such an evaluative process could be performed for UMTRA Project sites that overlie Class II waters. At a specific site, should analysis demonstrate to the MRC's satisfaction that complete restoration is unnecessary to protect long-term human health and the environment, then partial or no restoration would occur. Therefore, the DOE requests that the EPA consider this alternative.

Additional comments on the topic of Class III groundwater are proviaed in Sections 5.0 and 6.0 or this report. 


\section{REFERENCES}

EPA (U.S. Enviromental Protection Agency), 1987a. Alterrate Concentration Limit Guidance, EPA 530-SW-87-017.

EPA (U.S. Enviromental Protection Agency), 1987b. Ground-Water Protection Standards for Inactive Uranium Tailings Sites, EPA 520/1-87-014.

EPA (U.S. Environmental Protection Agency), 1986. Final draft for Guidelines for Ground-Water Classification Under the Ground-Water Protection Strategy, November, 1986.

EPA (U.S. Environmental Protection Agency), 1985. Criteria Document for Uranium in Drinking Water," Criteria and Standards Division, Office of Drinking Water, Washington D.C.

Illinois State Water Survey, 1981. "A 'Random-Walk' Solute Transport Model for Selected Groundwater Quality Evaluations," Illinois Department of Energy and Natural Resources, ISWS/BUC $-65 / 81$.

National Research Council, 1986. "Scientific Basis for Risk Assessment and Management of Uranium Mill Tailings," prepared by the National Research Council, Uranium Mill Tailings Study Panel Board on Radioactive Waste Management, Commission on Physical Sciences, Mathematics, and Resources, National Academy Press, Washington, D.C. 
APPENDIX A

AQUIFER RESTORATION AND

POST-DI SPOSAL MONI TOR ING C'JNSIDERATIONS

AND COST ESTIMATES 
This appendix describes the procedure used to estimate costs of aquifer restoration and post-disposal monitoring at each of the UMTRA Project sites. Basically, the procedure for estimating aquifer restoration was to model the aquifer parameters and contaminant conditions that would affect costs at five sites judged to typify all of the sites. (At one site (Falls City), four separate plumes were modeled.) The cost elements so generated were then applied to the known aquifer and contaminant characteristics at the other, unmodeled sites to calculate site costs.

Post-disposal monitoring includes the costs of monitoring ambient groundwater at disposal sites that is not contaminated and is currently expected not to need remediation. 
The proposed EPA standards require groundwater restoration on the basis of MCLs of 13 constituents. As currently proposed, the most complete and expensive level of restoration would be to restore all contaminated groundwater at all sites to the higher of the proposed MCLs or background levels for all 13 constituents. (A)though not specified in the proposed regulations, an even more rigorous and expensive level of restoration would be to meet the EPA proposed standards and to meet additiollal, more stringent, state/tribe standards.) Less stringent cleanup criteria would include:

- Active restoration of only that groundwater that would exceed the standards considering natural flushing, and

- In addition to natural flushing, the consideration of ACLs and supplemental standards, where appropriate.

Aquifer restoration option

Several active cleanup options are available. These options include:

- Extraction and discharge.

- Extraction, treatment, and discharge.

- Lixiviant injection, extraction, treatment, and discharge.

Contaminated groundwater can be extracted with wells or trenches. The use of trenches is limited to relatively shallow contamination (generaliy less than 100 feet deep) and is most useful in materials with low permeability. For most cases where the contamination is in permeable materials and in cases of low permeability but deep contamination, wells are the preferred extraction method.

The need for treacment prior to discharge, including possible reinjection into an aquifer, depends upon the concentrations of contaminants in the extracted groundwater and the regulations regarding discharge of effluent to surface and groundwater. If appropriate concentration limits are exceeded in the extracted water, treatment would be required. It is anticipated that treatment will be required. However, the cortaminant concentrations with in the piume may nominally exceed appropriate limits; a sufficient volume of uncontaminated water may be extracted with the contaminated water such that the composite water contains concentrations that are less than the regulated limits. In these situations, the extracted water may be discharged without treatment.

Various thoos for treatment of the contaminated water are available. most of the treatment methods are chemical. These include chemical precipitation, coagulation, ion exchange, flocculation, neutralization, sorption, and reverse osmosis. Contamination can be separated physically from water using evaporation ponds. Biological treatment can be used to transform nitrate to nitrogen gas and oxygen gas. The preferred treatment methods depend on the specific mix of contaminants, the concentration of the contaminants, the general water quality, the volumetric flow of the treatment stream, and the available area for treatment facilities. 
In addition to above-ground treatment, two in-situ treatment methods may be applied. These are lixiviant injection and permeable treatment beds or walls. Both methods can be used to cause reducing geochemical conditions which would cause the trace metal contaminants to precipitate or adsorb out of solution into the solid phase. Although chemical reduction could reduce solute concentrations to less than the appropriate concentration limits, dissolution or desorption could occur as the geochemical environment reequilibrates. Therefore, chemical reduction does not provide long-term assurances that adequate water quality could be maintained.

The preferrea in-situ treatment would result in mobilizing the contaminant by causing oxidized conditions so that the contaminant can be removed expeditiously from the subsurface. Permeable treatment beds or walls cannot be used effectively for this purpose. Injection of oxidizing lixiviants containing hydrogen peroxide or oxygen to oxidize the system and sodium bicarbonate to increase the $\mathrm{pH}$ may be useful for removing contaminants that may leach from the solid phase. Although this technology is unproven, it may be the only practicable method to remove trace metal contamination, primariiy in the solid phase, but leaches to the groundwater at concentrations above the acceptable concentration limits.

Lixiviants would be introduced by injection or inflitration upgradient of the contamillation. The lixiviant would move through the contaminated zone, interact with the liquid and solid phases, become impregnated with contaminants, and be extracted at the leading edge of the contaminant plume.

Following the extraction, or extraction and treatment, of contaminated water, the water would be discharged. Options for discharge include:

- Discharge to surface water.

- Infiltration.

- Injection in shallow wells.

- Injection in deep wells.

The chosen option would be the least expensive, most efficient, acceptable option and would be based on case specific consiaerations.

Aquifer restoration simulations

A two-part solute transport simulation process was developed based on the Random Walk algorithm (IIlinois State Water Survey, 198i). The first part was used to calibrate the input parameters of the solute transport simulation against field water quality data. The second part was used to simulate various aquifer restoration scenarios with design parameters as output.

The calibration procedure follows:

1. Superimpose a rectangular grid over the plume map. The grid can have up to 50 equally spaced columns and 50 equally spaced rows. The spacing between columns can be different than the spacing between rows. 
2. Idealize the source area as a rectangle. Uetermine the grid coordinates of the corners of the rectangle.

3. Determine the temporal distribution of the source term.

4. For sites where more than one contaminant plume was modeled, calibrate the distribution of contamination for the contaminant with the most uniform and longest plume first. At most sites, the first calibration was for uranium or nitrate. Longitudinal and transverse dispersivity were calibrated for this first contaminant.

5. For each contaminant, eight to 14 nodes were chosen for calioration. Determine the nodal coordinates for each node with the nodal origin being the upper, left corner of the grid. Determine the contaminant concentration for each calibration node.

6. Determine and input values for transmissivity, hydraulic conductivity, storativity, effective porosity, flow rate in the $x$ direction, flow rate in the $y$ direction, the source location, the number of particles representing the source, the number of time periods for source release, and the fraction of the total contamination released during each time period.

7. Calibrate longitudinal dispersivity and transverse dispersivity for the first contaminant along with the retardation coefficient for the specific contaminant. Assign the ranges for all three parameters (iongitudinal dispersivity, transverse dispersivity and retardation coefficient) and the desired number of points with in the ranges for the calibration process. For each permutation within the ranges of longitudina) dispersivity, transverse dispersivity and retardation coefficient, the prescribed concentration and calculated concentration were compared and the sum of the absolute differences were determined. The optimal set of parameter values produced the least absolute difference of the comparison of prescribed concentrations to calculated concentrations.

8. Following determination of the optimal longitudinal dispersivity and transverse dispersivity with the calibration for the first contaminant, calibrate the retardation coefficients for the other contaminants by varying the retardation coefficients through a prescribed range and determining the least absolute difference.

Based on the calculated distribution of particles within the calibrated plume governed by the calibrated set of input parameters, five aquiter restoration options were simulated. These were:

1. Extraction of the contaminated groundwater using wells or trenches for a specified duration or until the concentration limit is satisfied throughout the flow freld.

2. Injection of a lixiviant, followed by extraction of the contaminated groundwater for specified duration or until the concentration iimits were satisfied throughout the flow field. 
3. Extraction of the $c$.aminated groundwater such that the concentration limits were satistied by the combination of active restoration and natural flushing with in 100 years.

4. Lixiviant injection followed by extraction such that the concentration limits were satisfied by a combination of active restoration and natural flushing within 100 years.

5. Natural flushing for 100 years or until the concentration limit is satisfied throughout the flow field.

The first option allowed simulation of one or more extraction systems and predicted the contaminant concentrations discharged to wells or trenches and the length of time required to satisfy concentration limits. The second option allowed simulation of injection of a lixiviant. The leachable mass of contaminant in the solid phase was calculated from the calibrated retardation coefficient, the estimated porosity, and bulk density of the aquifer. It was assumed that the lixiviant could mobilize the leachable contaminant from the solid phase; i.e., the retardation coefficient could be reduced to 1.0 . The third and fourth options are the same as options two and three respectively, except that natural flushing was used following active cleanup to reduce the concentration to the acceptable limit. The fifth option was used to determine if natural flushing alone could lower concentrations to below limits with in a 100-year period. (Modeling indicated that natural flushing could not achieve the MCLs within 100 years; thus, this option was not considered in detail.)

Five UMTRA Project sites having plumes of contaminated groundwater were selected as examples, and were modeled. One of these, the Falls City site, was divided into four separate source areas and four separate contaminant plumes (FP5, FR2, FM1, and FU1). A summary of the input to and the output from the five modeled sites is included in this section.

Taole A.i includes the key input parameters to the calibration process and the calibrated dispersivity valves. The input parameters are transmissivity in units of gallons per day per foot $(T)$, storativity $(S)$, hydraulic conductivity in units of gallons per day per foot squared $(K)$, porosity $(N)$, and velocity in units of feet per day $(V)$. Output parameters from the calibration include longitudinal dispersivity in units of feet $\left(D_{1}\right)$ and transverse dispersivity in units of feet $\left(D_{t}\right)$.

Table A.2 includes the calibrated retardation coefticients and calculated mass of dissolved contaminants for each modeled contaminant at each modeled site. The mass was calculated by considering the prescribed concentrations at each calibration node and the ratio of the mass at all the calibration nodes relative to the total mass of the plume.

Table A.3 includes the aquifer design parameters for the various options modeled at each site. This taule indicates whether the use of trenches or weils was simulated, the estimated yield to each well or trench, the dimensions of the simulated wells or trenches, and the expected duration of the operation.

Additional supporting information is available in the DOE UMTRA Project Office, Albuquerque, New Mexico. 
Table A.1 Input and calituration parameters

\begin{tabular}{|c|c|c|c|c|c|c|c|}
\hline & $\left(\mathrm{gpd}^{T} / f t\right)$ & $\mathbf{S}$ & $\left(g p d / f t^{2}\right)$ & $N$ & $\begin{array}{c}V \\
(f t / \text { day })\end{array}$ & $(\mathrm{ft})$ & $\left(\mathrm{ft}_{t}\right.$ \\
\hline GUN & 75800 & 0.1 & 585 & 0.1 & 3.1 & 1506 & 85 \\
\hline TUB & 500 & 0.2 & 3.4 & 0.2 & 0.38 & 300 & 60 \\
\hline RVT & 5880 & 0.3 & 420 & 0.3 & 0.43 & 475 & 30 \\
\hline LKV & 682.5 & 0.15 & 10.5 & 0.15 & 0.093 & 12.78 & 52.2 \\
\hline FPG $(U)^{\star}$ & 300 & 0.4 & 15 & 0.4 & 0.2 & 525 & 12 \\
\hline FP6 $(R a)^{\star}$ & 300 & 0.4 & 15 & 0.4 & 0.2 & 660 & 130 \\
\hline FR $2^{\star}$ & 300 & 0.4 & 15 & 0.4 & 0.15 & 140 & 9 \\
\hline $\mathrm{FMI}^{\star}$ & 300 & 0.4 & 15 & 0.4 & 0.15 & 580 & 250 \\
\hline $\mathrm{FU}_{\perp}{ }^{\star}$ & 300 & 0.4 & 15 & 0.4 & 0.25 & 210 & 290 \\
\hline
\end{tabular}


Table A.2 Calibrated retardation coefficients (Rd) and solute contaminant masses

\begin{tabular}{llcr}
\hline Site & Contaminant & Rd & Mass (Kg) \\
& & & \\
LKV & Arsenic & 2.5 & 42.1 \\
LKV & Selenium & 4.5 & 14.0 \\
LKV & Cadmium & 1.0 & 21.9 \\
LKV & Chromium & 1.1 & 30.3 \\
LKV & Molybdenum & 1.8 & 105 \\
GU: & Uranium & 12.1 & 1320 \\
GUN & Cadmium & 81.8 & 59.1 \\
GUN & Selenium & 148.5 & 55.4 \\
RVT & Molybdenum & 4.7 & 373 \\
RVT & Uranium & 1.256 & 1470 \\
TUB & Nitrate & 1.0 & 050 \\
TUB & Cadmium & 1.06 & 158 \\
TUB & Selenium & 1.03 & 1750 \\
TUB & Uranium & 1.03 & 30,500 \\
FP6 & Uranium & 1.0 & $1.1 \times 10^{-4}$ \\
FP6 & Radium & 1.0 & $1.2 \times 10^{-6}$ \\
FR2 & Radium & 1.0 & 35,000 \\
FMi & Molybdenum & 1.0 & 46,700 \\
FUi & Uranium & 1.0 & \\
& & & \\
\hline
\end{tabular}

${ }^{\star}$ FCT. 


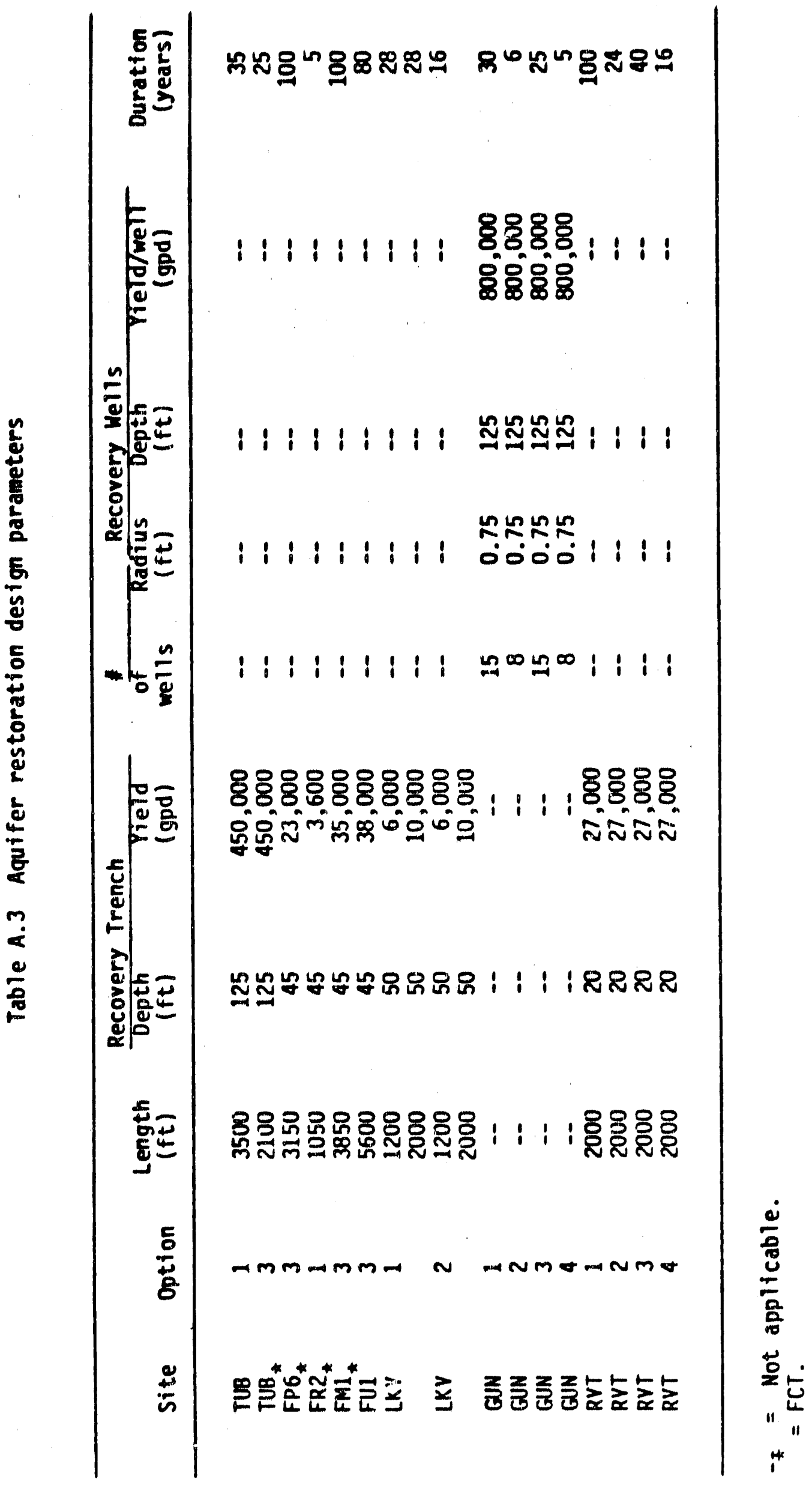


Aquifer restoration costs were estimated for the five example sites by applying each of the four active or active/passive cleanup methods described above. The five sites for which estimates were produced are Gunnison, Riverton, Lakeview, Falls City, and Tuba City.

The principle cost items in the estimates were:

- The duration of cleanup and monitoring.

- The extraction method and specifications.

- The transportation specirications.

- The prescribed treatment method.

- The discharge method and specifications.

- If required, the specifications for the lixiviant injection system.

- Where needed, the specifications for the supply of alternate water.

The estimates are for groundwater restoration simulations that satisfy the proposed EPA maximum concentration limits using active cleanup or a combination of active cleanup and passive restoration. Alternate concentration limits and supplemental standards were not considered in these estimates. Up to four restoration options were considered for five sites (Gunnison, Riverton, Labaview, Falls city, and Tuba (ity). The costs for these five sites were extrapol : $2 d$ to the other 19 sites. Ali cost estimates are preliminary. Additional da:d and analyses are needed for every site before a conceptual design can be prepared. Additional data and analyses could show that some of the options are not feasible or could support the design and implementation of more efficient, less expensive options.

The following procedure was usea to derive cost estimates for aquifer restoration for each of the UMTRA Project sites.

1. Estimate the mass of contaminants in the groundwater and the water leachable mass of contaminants in the saturated soll at each of the 24 UMTRA Project processing sites. The contwminants are those 12 constituents for which the EPA is proposing maximum concentration limits. (Gross alpha is not ilicluded.)

2. Determine a factor based on the estimated contaminants masses relative to the concentration itimits. The formula for the factor is:

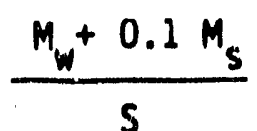

where: 
$M_{w} \quad$ - estimated mass of dissolved contamination in mg.

$M_{s}$ - estimated mass of leachable soll/rock-bound contamination in mg.

S. the proposed maximum concentration $1 \mathrm{imit} / 11 \mathrm{mg} / 1$.

The factor welghs the importance of contamination already in the water as 10 times that of the contamination in the soll because the contamination in the soll may leach at concentrations less than the standard. Also, the estimates for the leachable contamination in the soll may be high because they were derived by water elutriations rather than in column experiments.

Table A.4 contains the contaminant mass estimates and calculated factors for all of the UMTRA Project sites and for each contaminant.

3. Develop up to four restoration options for five example sites. These option are based on callbrating a solute transport algorithm with field data, then using the same algorithm to simulate various arrangements of pumping and injection.

4. Develop cost estimates for each simulated option.

5. Determine the factors that control the costs for the chosen sites and chosen options. Rank these factors according to their importance in cost determination and qualitatively describe these factors for each of the five modeled sites. Table A.5 shows these rankings and descriptions determined from the modeled sites.

6. For each of the 19 unmodeled sites choose the modeled site whose conditions (factors) most closely resemble the conditions at the unmodeled site. The chosen modeled site similar to the unmodeled site is indicated on Table A.6.

7. Extrapolate the costs for the similar modeled site to the unmodeled sites. The formula for this extrapolation is $0.25 \times$ cost at the modeled site $+0.75 \times$ cost at the modeled site $x$ (total contamination factor at the unmodeled site/total contamination factor at the modeled site). This formula is based on the assumption that, at the modeled sites, approximately 25 percent of the costs are fixed capital costs and 75 percent of the costs are for operation and maintenance $(0 \& \mathrm{M})$ costs, and that $O M$ costs will vary relative to the total contamination factor.

Estimated costs are presented on Table A.6. The cost estimates for physically implementing aquifer restoration are listed as the base costs. The project costs are the base costs multiplied by 2.8 . The derivation of this multiplier is described in Section 5.0. The summary costs are the least cost options for the one to four options simulated and costed. 


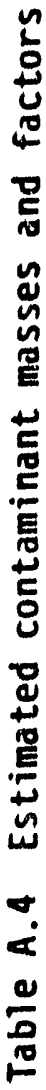

둔

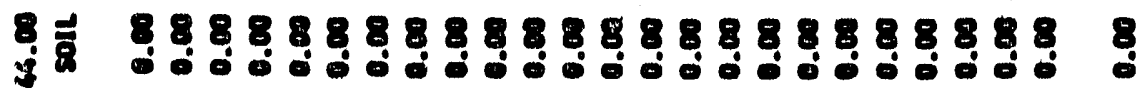

E

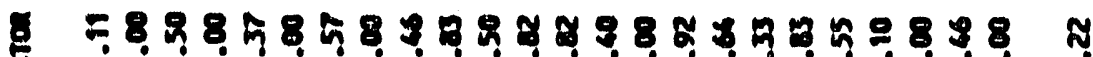

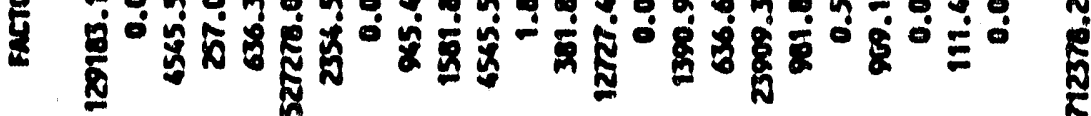

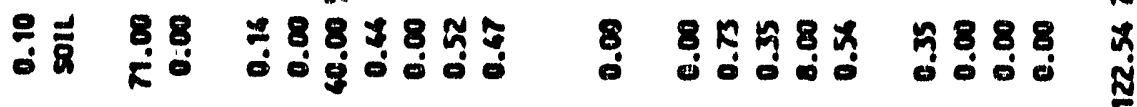

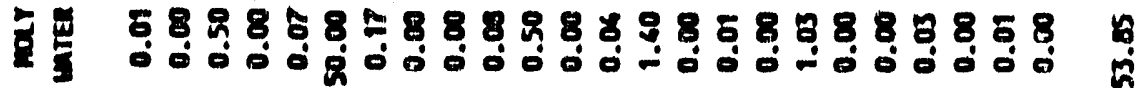

8 \%

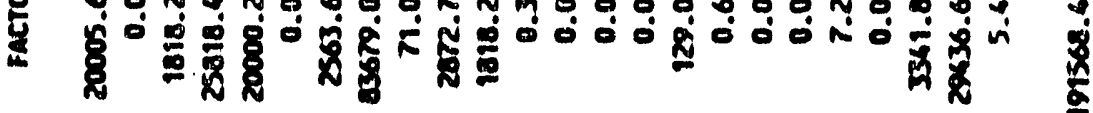

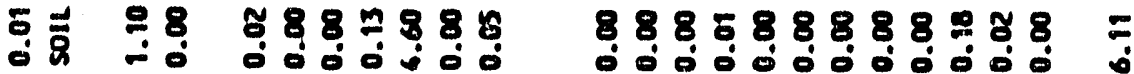

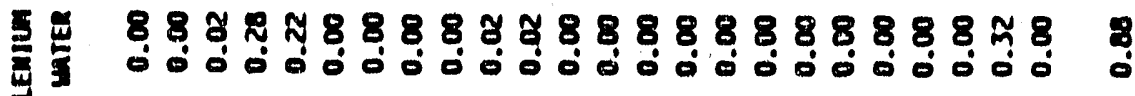

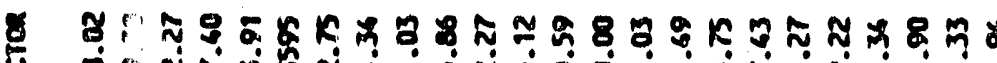

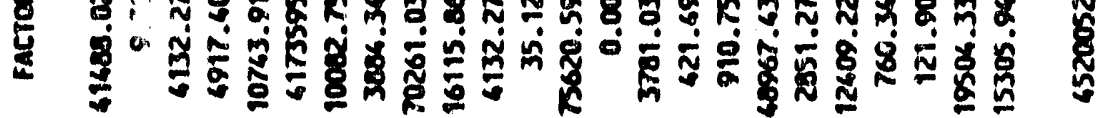

过

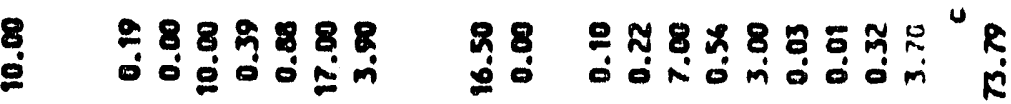

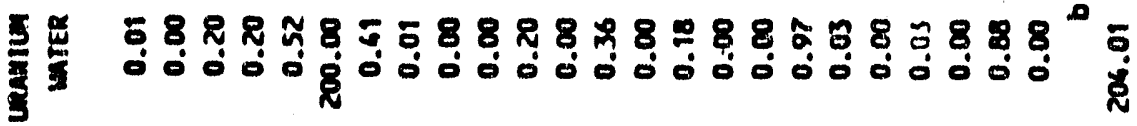

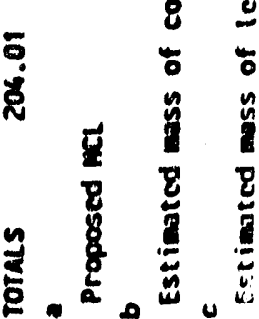




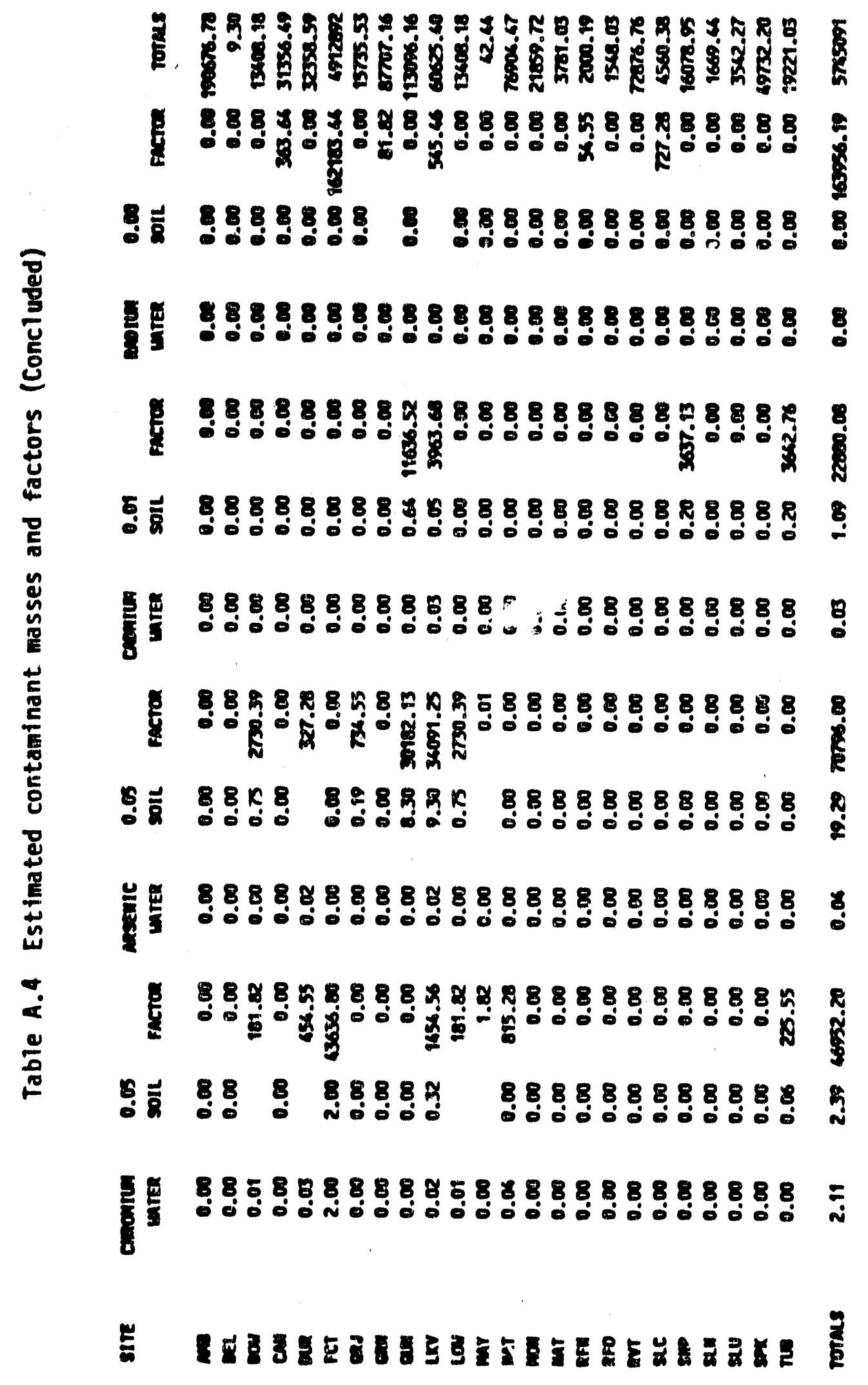




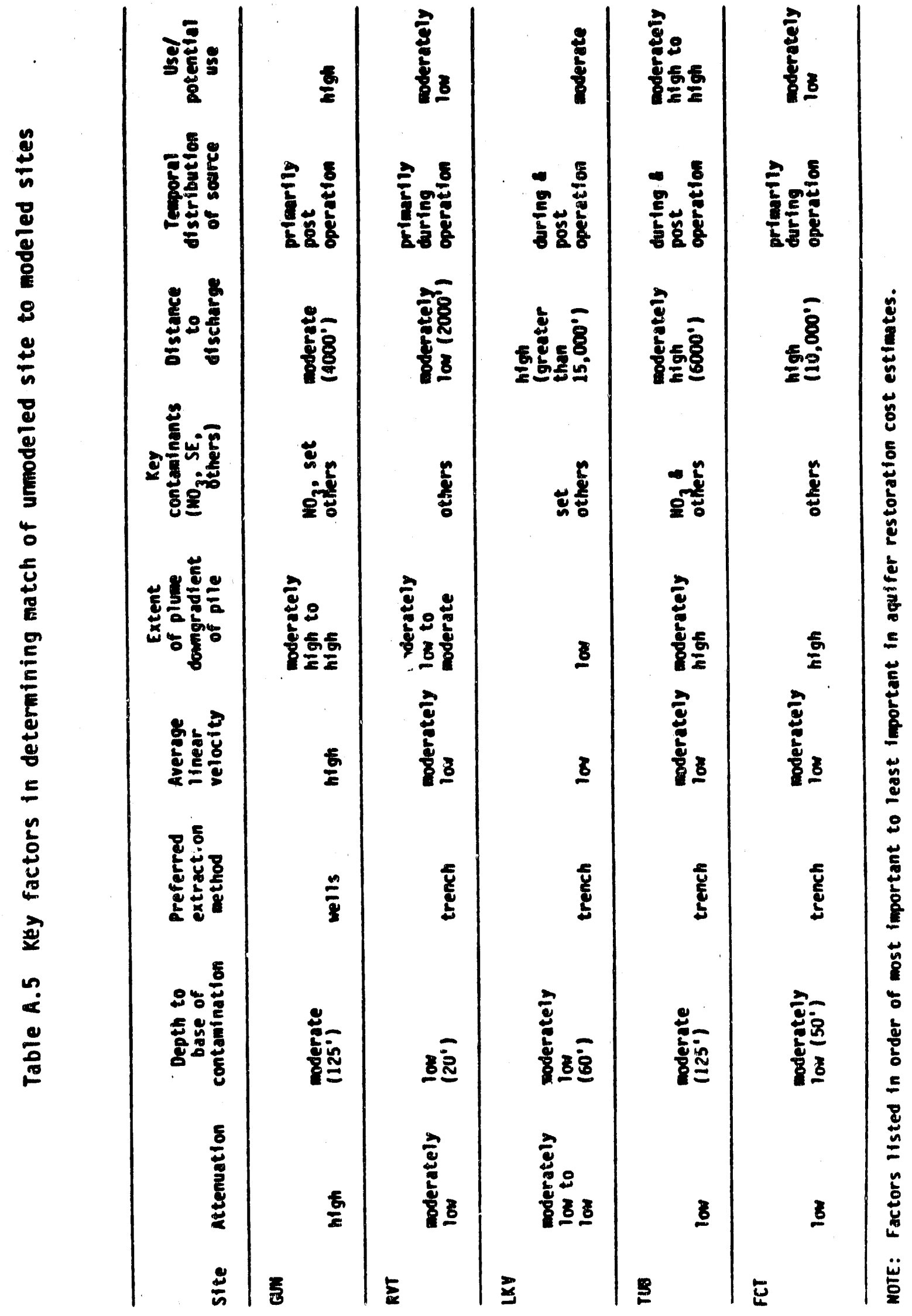




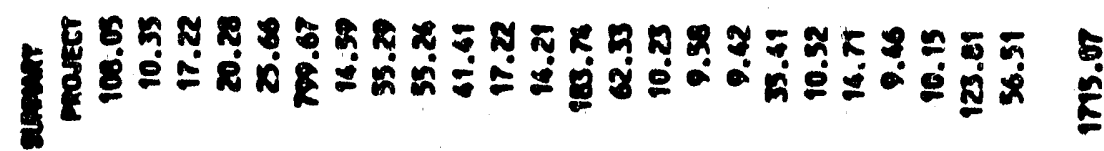

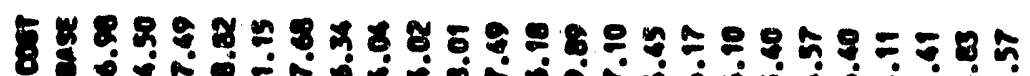

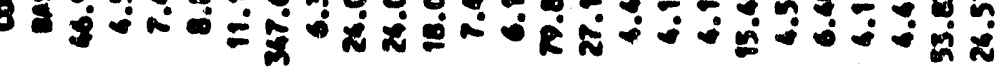
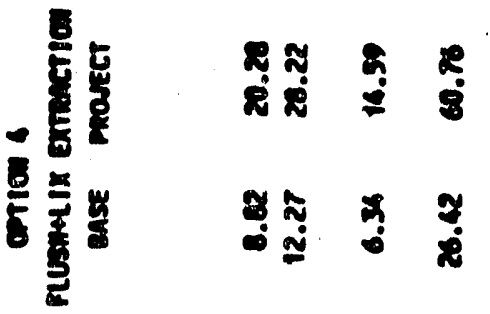

จุำ

क⿺辶่

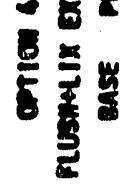

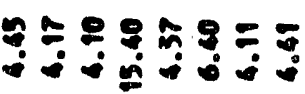

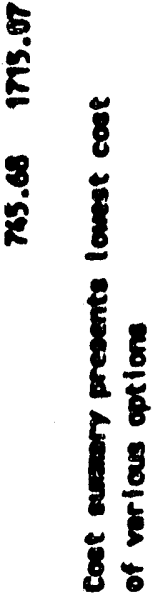

동

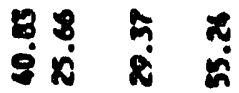

๊

3

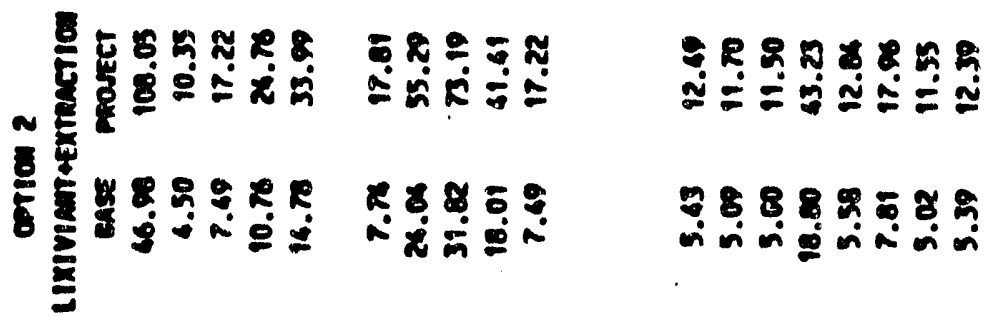

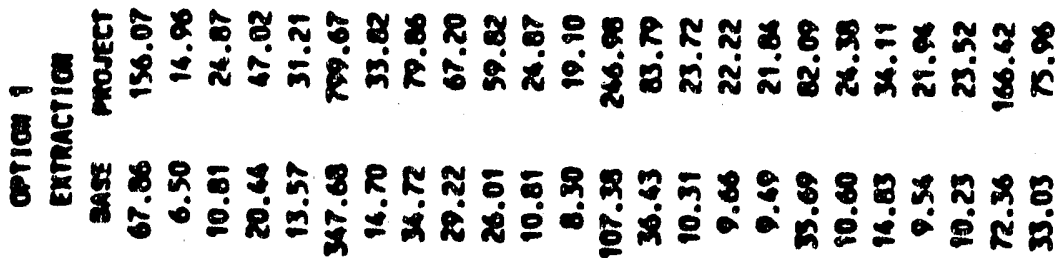

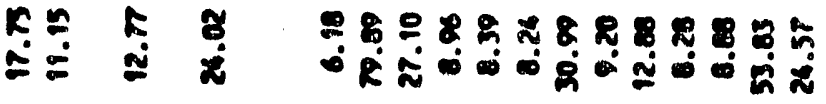

Еั

$\frac{\text { वें }}{\stackrel{0}{0}}$

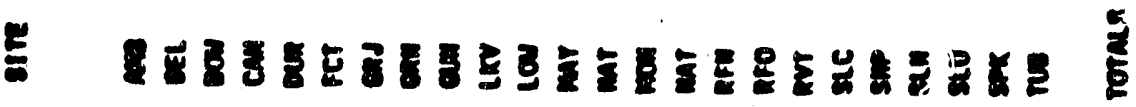


In adaition to aquifer restoration, the proposed EPA standards would require post-disposal compliance monitoring. The cost estimate for this monitoring, in 1987 dollars, follows:

Cost estimate assumptions for post-disposal monitoring are:

- Wells will be installed at 24 UMTRA Project processing sites and 10 disposal sites.

- Of these 34 sites, 22 sites will require wells deeper than 100 feet and 12 sites will require wells at a depth of approximately 25 feet.

- Eight wells will be required for the average site.

- Thirty years of post-disposal compliance monitoring will be required at the average site; no detection monitoring will be required.

o The average well will last for 10 years.

- The total number of deep wells is 22 sites $\times 8$ wells/site $\times 3$ replacements $=528$ deep wells.

0 The total number of shallow wells is 12 sites $\times 8$ wells/site $\times 3$ replacements $=288$ shallow weilis.

- Six days will be required to sample the average UMTRA Project site using a team of two water sampling specialists.

- Each water sampling specialist will work 204 field days per year (i.e., each team will sample 34 sites per year).

- The sampling frequency will be quarterly for the first three years, semiannually for the next three years, and annually for the last 24 years.

- Four sampling teams will be required for the first three years, two teams for the next three years, and one team for the last 24 years.

o The total number of water sampling specialist-years will be:

4 teams/year $\times 2$ specialists/team $\times 3$ years +

2 teams/year $\times 2$ specialists/team $\times 3$ years +

1 team/year $\times 2$ specialists/team $\times 24$ years $=$

BC. sampler-years.

- Sampling trucks will be replaced every three years.

- Four sampiing irucks will be required for the first three years, two trucks for the next thrce years, and eight trucks for the last 24 years.

- The total number of sampling trusks is 14. 
- The total number of sampling truck-years is 14 trucks $\times 3$ years/truck 42 truck-years.

- On the average, 14 samples will be analyzed per site: eight samples, four split samples, one known sample, and one field blank.

- The samples collected during the first three years will be analyzed for a full suite of inorganic constituents; samples collected during the last 27 years will be analyzed for a reduced suite including the major fons and contaminant indicator constituents.

- The number of full suite analyses will be 34 sites $\times 3$ years $\times 4$ suites/ year $x 14$ analyses/suite $=5,712$ full suite analyses.

- The number of reduced suite analyses will be:

34 sites $\times 3$ years $\times 2$ suites/year $\times 14$ analyses/suize +

34 sites $\times 24$ years $\times 1$ suite/year $\times 14$ analyses/suite =

14,280 reduced suite analyses.

- The number of known solutions will be:

34 sites $\times 3$ years $\times 4$ suites/year $\times 1$ known $/$ suite +

34 sites $\times 3$ years $\times 2$ suites/year $\times 1$ known/suite +

34 sites $\times 24$ years $\times 1$ suite/year $\times 1$ known/suite $=$ $i, 428$ known solutions. 
Table A.7 Thirty-year cost estimate for post-disposal monitoring

\begin{tabular}{|c|c|c|c|c|c|}
\hline Item & $\begin{array}{l}\text { Description } \\
\text { of item }\end{array}$ & $\begin{array}{l}\text { Unit } \\
\operatorname{cost}(\$)\end{array}$ & $\begin{array}{c}N \text { in } \\
\text { of units }\end{array}$ & $\begin{array}{c}\text { Base } \\
\text { cost } \\
\text { (smillion) }\end{array}$ & $\begin{array}{c}\text { Project } \\
\text { cost } \\
\text { (smillion) }\end{array}$ \\
\hline Install well & Deep well & 4,000 & 528 & 2.11 & 4.86 \\
\hline Install well & Shallow well & 2,000 & 288 & 0.58 & 1.32 \\
\hline Abandon well & Deep we 11 & 1,000 & 528 & 0.53 & 1.21 \\
\hline Abaridon well & Shallow well & 500 & 288 & 0.14 & 0.33 \\
\hline Burdened labor costs & Samp ler/year & 70,000 & 84 & 5.88 & 13.52 \\
\hline Per diem & Sampler/day & 100 & 17,136 & 1.71 & 3.94 \\
\hline Purchase truck & Truck & 30,000 & 14 & 0.42 & 0.97 \\
\hline Maintain truck & Truck-year & 10,000 & 42 & 0.42 & 0.97 \\
\hline Sample analysis & Full suite & 300 & 5,712 & 1.71 & 3.94 \\
\hline Sample analysis & Reduced suite & 150 & 14,280 & 2.14 & 4.93 \\
\hline Make known solutions & Solution & 500 & 1,428 & 0.7 & 1.64 \\
\hline & & & & 16.36 & 37.64 \\
\hline
\end{tabular}

Note: Project costs are base costs $\times 2.3$ (see Section 4.2). 

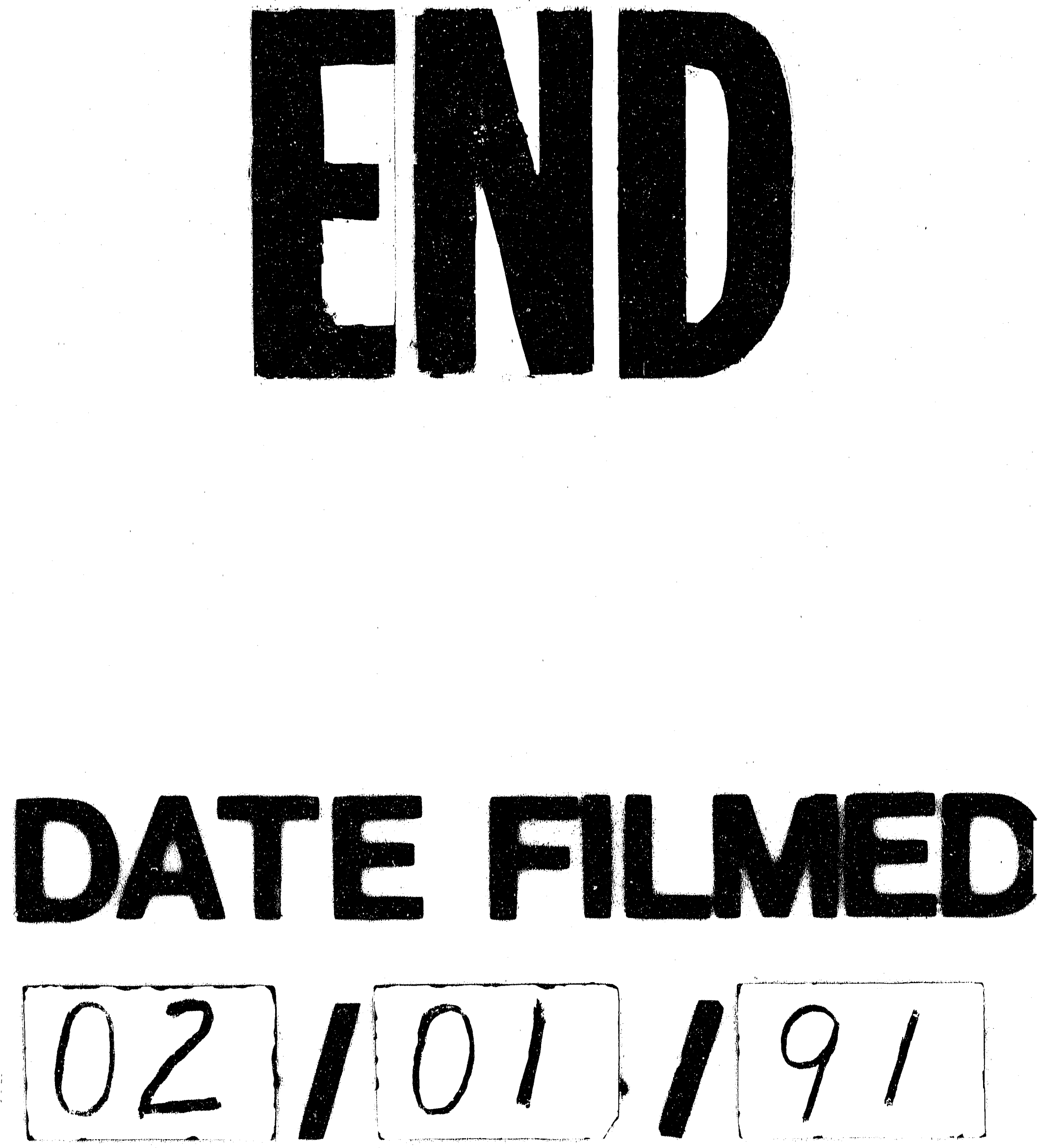
